\title{
Making the most of mitochondrial genomes - Markers for phylogeny, molecular ecology and barcodes in Schistosoma (Platyhelminthes: Digenea)
}

\author{
M.Z. Zarowiecki a, T. Huyse ${ }^{\text {a,b }}$, D.T.J. Littlewood ${ }^{\mathrm{a}, *}$ \\ ${ }^{a}$ Wolfson Wellcome Biomedical Laboratories, Department of Zoology, Natural History Museum, Cromwell Road, London SW7 5BD, UK \\ ${ }^{\mathrm{b}}$ Katholieke Universiteit Leuven, Laboratory of Aquatic Ecology, Ch. Deberiotstraat 32, B-3000 Leuven, Belgium
}

Received 22 February 2007; received in revised form 19 April 2007; accepted 24 April 2007

\begin{abstract}
An increasing number of complete sequences of mitochondrial $(\mathrm{mt})$ genomes provides the opportunity to optimise the choice of molecular markers for phylogenetic and ecological studies. This is particularly the case where mt genomes from closely related taxa have been sequenced; e.g., within Schistosoma. These blood flukes include species that are the causative agents of schistosomiasis, where there has been a need to optimise markers for species and strain recognition. For many phylogenetic and population genetic studies, the choice of nucleotide sequences depends primarily on suitable PCR primers. Complete mt genomes allow individual gene or other mt markers to be assessed relative to one another for potential information content, prior to broad-scale sampling. We assess the phylogenetic utility of individual genes and identify regions that contain the greatest interspecific variation for molecular ecological and diagnostic markers. We show that variable characters are not randomly distributed along the genome and there is a positive correlation between polymorphism and divergence. The $\mathrm{mt}$ genomes of African and Asian schistosomes were compared with the available intraspecific dataset of Schistosoma mansoni through sliding window analyses, in order to assess whether the observed polymorphism was at a level predicted from interspecific comparisons. We found a positive correlation except for the two genes (coxl and nadl) adjoining the putative control region in $S$. mansoni. The genes nad1, nad4, nad5, coxl and cox3 resolved phylogenies that were consistent with a benchmark phylogeny and in general, longer genes performed better in phylogenetic reconstruction. Considering the information content of entire mt genome sequences, partial coxl would not be the ideal marker for either species identification (barcoding) or population studies with Schistosoma species. Instead, we suggest the use of $\operatorname{cox} 3$ and nad5 for both phylogenetic and population studies. Five primer pairs designed against Schistosoma mekongi and Schistosoma malayensis were tested successfully against Schistosoma japonicum. In combination, these fragments encompass $20-27 \%$ of the variation amongst the genomes (average total length $\sim 14,000$ bp), thus providing an efficient means of encapsulating the greatest amount of variation within the shortest sequence. Comparative mitogenomics provides the basis of a rational approach to molecular marker selection and optimisation.
\end{abstract}

(C) 2007 Australian Society for Parasitology Inc. Published by Elsevier Ltd. All rights reserved.

Keywords: Molecular markers; mtDNA; Schistosomes; Phylogeny; Population genetics; Mitogenomics

\section{Introduction}

The family Schistosomatidae (Platyhelminthes: Digenea) includes 14 genera and some 100 species of blood fluke (Basch, 1991; Khalil, 2002). All are obligate parasites of

\footnotetext{
* Corresponding author. Tel.: +44 207942 5742; fax: +44 2079425151 .

E-mail address: T.Littlewood@nhm.ac.uk (D.T.J. Littlewood).
}

birds or mammals and use freshwater gastropods as intermediate hosts to complete their life cycle. The schistosomatids include a number of species of significant medical, veterinary and economic importance. Schistosomiasis, the disease caused by the parasite when it parasitises its definitive host, is particularly important in humans, with over 200 million people recorded as having infection per year (WHO, 2001). This disease is endemic in 74 tropical 
developing countries with some 600 million people at risk. There are six species of Schistosoma known to parasitise humans as definitive hosts including, Schistosoma japonicum, Schistosoma malayensis, Schistosoma mekongi, Schistosoma mansoni, Schistosoma guineensis, Schistosoma intercalatum and, to a much lesser extent with only isolated reports, Schistosoma mattheei (more commonly found in cattle); it is possible that reports of $S$. mattheei are in fact hybrids between $S$. mattheei and Schistosoma haematobium (Kruger and Evans, 1990). Understanding and controlling schistosomiasis requires an understanding of evolutionary history, host-parasite interactions and epidemiology. Accurate species and strain identification is key to successful epidemiological studies, monitoring and control. Increasingly, molecular-based methods are being developed and implemented for accurate, rapid and highthroughput identification, but to date such methods have relied on a poorly informed approach to the selection of appropriate molecular markers.

In general, the choice of molecular markers is governed by balancing a suite of factors (including cost, proven utility and likely efficacy) matched to the desired purpose for which they have been selected. It is at best dictated by preliminary empirical studies, but usually proceeds through an assessment of results as they accumulate, with the disadvantage of ambiguous or uninformative markers being recorded simultaneously (Morgan et al., 2005). There is a certain degree of conservatism in the approach; researchers tend to re-use PCR primers from authors who have worked on the same or similar taxa. Thus, such primers become widely used and are sometimes chosen even if they do not represent the most suitable marker. The pursuit of a universal DNA 'barcoding' region (Hebert et al., 2003a,b; Hebert and Gregory, 2005) has contributed to this conservatism, and large projects for species identification and phylogeny are encouraged to rely primarily (or even exclusively) on partial mitochondrial (mt) cytochrome $c$ oxidase I ( $\operatorname{cox} 1)$, even though this marker may not be the most informative or most suitable marker for all taxa (Moritz and Cicero, 2004; Will et al., 2005).

Among flatworms there is no established precedent as to which molecular markers should be used or for what purpose. Popular nucleotide sequences for phylogenetic assessment have included the complete small (SSU) and variable domains D1-D3 of the large (LSU) nuclear subunit rRNA genes (e.g., Littlewood and Olson, 2001; Lockyer et al., 2003a; Littlewood, 2006) and, to a much lesser extent, coxl (e.g., Olson and Tkach, 2005). This is also the case for schistosome phylogenetics (Lockyer et al., 2003b; Morgan et al., 2003). In contrast, phylogeographic studies have relied almost exclusively on partial coxl (e.g., Iwagami et al., 2003; Pongratz et al., 2003; Wickström et al., 2003) and, to a lesser extent, on ribosomal DNA (Attwood et al., 2002). Population genetic studies of flatworms are few, and have focussed on the accumulation of data from random amplified polymorphic DNA (RAPD) analyses (e.g., Semyenova et al., 2003; Vilas et al., 2003; Theron et al., 2004). Targeted gene approaches have relied heavily on mt markers, including coxl (e.g., Wickström et al., 2003), nadl (Criscione and Blouin, 2004) and/or multiple $\mathrm{mt}$ fragments (Morgan et al., 2005).

New and potentially informative molecular data have been accumulated for species of Schistosoma from genome projects (e.g., El-Sayed et al., 2004), expressed sequence tag (EST) projects (e.g., Franco et al., 1995), phylogenetic studies (e.g., Lockyer et al., 2003b) and post-genomic research programmes focusing on gene function (e.g., Oliveira et al., 2004). Genomic data have been examined for repeat motifs for the identification of and characterisation of microsatellite markers (Rodrigues et al., 2002, 2007). Importantly, another potential source of molecular markers of schistosomes has emerged recently. There now exist completely characterised $\mathrm{mt}$ genomes of five species $(S$. mansoni, S. japonicum, S. mekongi, S. haematobium and Schistosoma spindale) and an almost complete genome for S. malayensis; four of these are human parasites. These data have arisen through phylogenetic and evolutionary studies and the desire to explore the extent to which a novel $\mathrm{mt}$ gene order is present within the genus (Le et al., 2000a, 2001; Littlewood et al., 2006). A comparative mitogenomic approach to identify diagnostic and highly variable molecular markers for population studies offers perhaps the best opportunity to assess existing mt markers and to identify regions of the genomes with potential. Few authors have considered $\mathrm{mt}$ sequences as potential markers for molecular ecological studies of schistosomiasis and yet their potential is well recognised (Curtis and Minchella, 2000). The ability to provide diagnostic markers for individual subpopulations may be within reach with full $\mathrm{mt}$ genome sequences. The most extensive population genetic study of schistosomes with mt markers is that of Morgan et al. (2005) and covers $\sim 2535 \mathrm{bp}$ from four marker regions on the $\mathrm{mt}$ genome for 143 specimens of $S$. mansoni from its entire geographical range. In the same study, nuclear (ribosomal internal transcribed spacers ITS- 1 and ITS-2) were also characterised, but very limited variation was detected (three variable positions in ITS-1).

Mitochondrial genomes are involved in the maintenance of the mitochondrion and its various functions in the eukaryotic cell. Many factors influence the evolutionary dynamics of nucleotide change within $\mathrm{mt}$ genomes, and these may act within individuals, populations and species lineages during phylogenesis (Ballard, 2000a,b); differential rates of genome replication and DNA repair, biases in base substitution, adaptive evolution and differential rates of heterogeneity are but some of the processes that contribute to mitochondrial sequence variation. Use of this variation within and between species has been exploited for a diversity of purposes in molecular ecology and phylogeography (Avise, 2004; Ballard and Whitlock, 2004). Mitochondrial genomes of flatworms include two ribosomal genes, 12 protein-coding (they lack atp8) and 22 transfer RNA (tRNA), and are 13,503-16,901 bp in length. An earlier review of $\mathrm{mt}$ genomes of schistosomes and their potential as a source of 
markers relied on the few Schistosoma species available at the time (Le et al., 2000b); the study lacked the cox3, nadl, nad4L, nad5 and 10 tRNA genes and included incomplete sequences for coxl, nad2 and cob. Many mt genomes are not fully sequenced as some regions, particularly noncoding repeat regions, are difficult to amplify or sequence; many 'completed' mt genomes have at least all the coding regions fully sequenced and characterised. There are very few genera for which more than one complete $\mathrm{mt}$ genome has been sequenced; exceptions include Homo (e.g., Torroni et al., 2006) and Drosophila (e.g., Ballard, 2000a). The data for Schistosoma offer an additional useful model system.

In this paper, complete mt genomes are assessed for their potential information content for research on species of Schistosoma. (i) The extent and magnitude of the phylogenetic information content in $\mathrm{mt}$ genomes is investigated; the performance of nucleotides and inferred amino acid sequences are each compared; (ii) the distribution of polymorphic sites (differences within a species) and divergent sites (differences between species) along the $\mathrm{mt}$ sequences is described and correlations sought; finally, (iii) the utility of comparing complete $\mathrm{mt}$ genomes of closely related species in identifying suitable markers for molecular phylogenetic and ecological studies is discussed. We chose to assess phylogenetic information content and nucleotide variability per unit length, allowing us to address two central questions: (i) how useful are individual genes at recovering species phylogenies, and (ii) which are the least and most variable regions of the schistosome mt genomes? Addressing the latter question allowed primer design for population genetic purposes.

\section{Materials and methods}

\subsection{Sequences utilised}

The $\mathrm{mt}$ genomes of $S$. mansoni (Accession No. NC_002545), S. japonicum (NC_002544), S. mekongi (NC_002529), S. haematobium (DQ157222) and S. spindale (DQ157223), and one almost complete genome for $S$. malayensis (AF29516) were used for this study. Additionally, for the phylogenetic analyses, we used the closest related outgroups with completely characterised $\mathrm{mt}$ genomes: the digeneans Fasciola hepatica (NC_002547) and Paragonimus westermani (NC_002354). Mitochondrial sequences of $S$. mansoni from multiple geographic isolates, used for assessing intraspecific variation, were taken from sequences detailed in Morgan et al. (2005).

\subsection{Alignments for phylogeny}

As a result of gene rearrangements in the $\mathrm{mt}$ genomes, entire genome sequences could not be aligned. Instead, individual rRNA and protein-coding genes were chosen for alignment. Transfer RNA genes were excluded as they may not be truly homologous based on their anticodon identity alone and are known in some taxa to remold and change through time, rendering them paralogous (Rawlings et al., 2003). Non-coding regions are unlikely to be homologous and were thus also excluded. Nucleotides and amino acids for individual genes were each aligned using ClustalW (Thompson et al., 1994) with default settings. The alignments were then inspected by eye and adjusted using MacClade 4.06 (Maddison and Maddison, 2000). Nucleotide sequences from protein-coding genes were aligned in frame with reference to their amino acid translation and the amino acid alignments. Ribosomal RNA genes were aligned with ClustalW and regions with ambiguous base positional homology were excluded. Alignments are available from the authors upon request.

\subsection{Alignments for sliding window analysis}

Using the same method as described in Section 2.2, complete genome alignments were made between closely related species (for which no gene order differences occurred), including tRNAs and all intergenic (non-coding) spaces. Pairwise alignments of complete genomes were made between the most closely related species, $S$. mekongi and $S$. malayensis, and $S$. haematobium and $S$. spindale. The complete genomes of the African S. mansoni, S. haematobi$u m$, and the Indian $S$. spindale were also aligned; hereafter referred to as the African-Indian group. In order to test the co-variation of polymorphism on different scales and different levels of phylogeny, mt data from Morgan et al. (2005) were aligned to each other and the corresponding region in the alignment of the complete $\mathrm{mt}$ genome sequences of the African-Indian group.

\subsection{Phylogenetic information content}

Three criteria were chosen to evaluate phylogenetic information content, (i) length variance and information content of individual genes, (ii) topological congruence and nodal support of phylogenies estimated from individual genes, and (iii) estimates of signal and noise in the individual data sets.

Phylogenies were constructed for each gene. Throughout the tests, all data were weighted equally (Baker and DeSalle, 1997; Wenzel and Siddall, 1999; Baker et al., 2001). For protein-coding genes, all codon positions were included, since the more variable third base positions have been demonstrated to give the inferred phylogeny higher resolution than if they are excluded (Källersjö et al., 1999; Baker et al., 2001). The test of substitution saturation (Xia et al., 2003) available in DAMBE (Xia and Xie, 2001) showed signs of saturation at the level of ingroup-outgroup comparison. Plotting transitions and transversions against Tamura-Nei distances showed a linear relationship only when third positions were excluded (Fig. 1). Protein-coding and ribosomal genes were analysed individually and as concatenated gene alignments in a single file. 


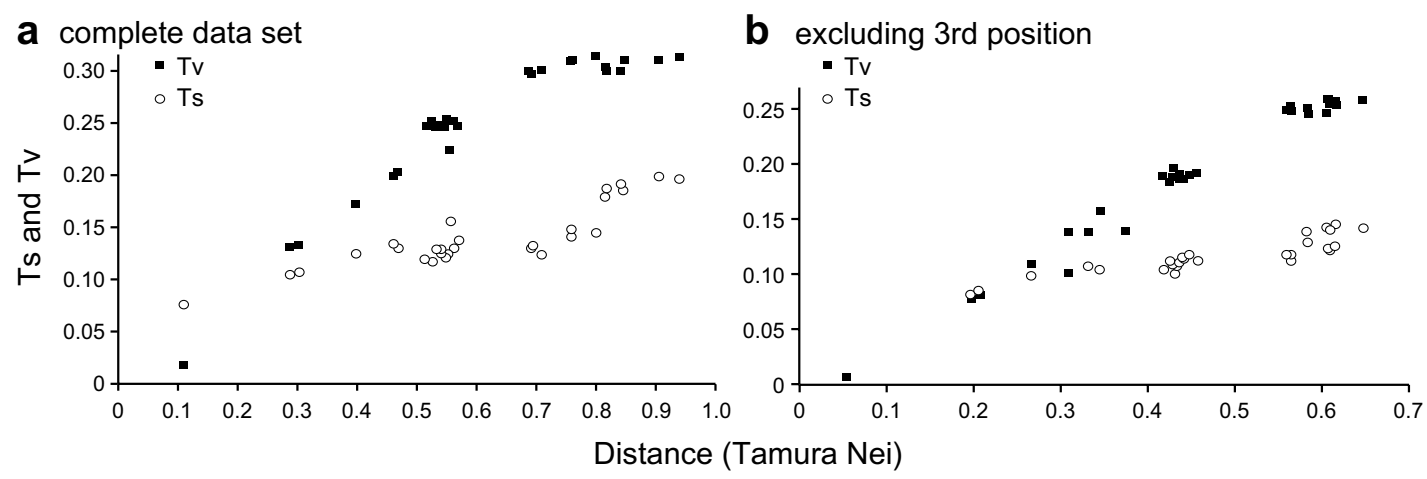

Fig. 1. Graphical plot of transitions (Ts) and transversions (Tv) against Tamura-Nei distances using DAMBE (Xia and Xie, 2001) on the complete dataset (a) and when the third base position is excluded (b).

Phylogenies were inferred using maximum parsimony (MP) and Bayesian inference (BI). MP analyses were performed in PAUP* v 4.0b10 (Swofford, 2002), using the heuristic search method (10 search replicates) and treebisection-reconnection (TBR) branch-swapping algorithm; all characters were unordered and were weighted equally, gaps were treated as missing data and majority consensus trees were constructed from nonparametric bootstrap replicates (Felsenstein, 1985). Bayesian analysis was performed with MrBayes 3.0b4 (Huelsenbeck and Ronquist, 2001). Models for sequence evolution were calculated using MrModeltest 2.2 (Nylander, J.A.A., 2004; Evolutionary Biology Centre, Uppsala University) and ProtTest 1.2.6 (Abascal et al., 2005), using the AIC criterion (Sakamoto et al., 1986), and included in the command block. For the concatenated nucleotide analyses, the genes were partitioned, and the parameters were allowed to vary independently. For the concatenated protein analysis, a single substitution model JTT $+\mathrm{G}$ (Jones et al., 1992) was employed; this was the most frequently optimal model chosen for the individual proteins with MrModeltest. However, the parameters were allowed to vary independently between genes. Temperatures were set individually for each partition in BI to ensure chain switching at a suitable rate.

The phylogeny proposed by Lockyer et al. (2003b), based on complete SSU ribosomal DNA (rDNA), complete LSU rDNA and partial mt coxl sequences, was used as a reference topology against which individual and combined gene phylogenetic analyses were compared; outgroup ((S. japonicum (S. malayensis, $S$. mekongi)), (S. mansoni $(S$. spindale, $S$. haematobium))). For the taxa used in the present study, the topology of the tree presented by Lockyer et al. (2003b) has been supported by numerous molecular studies (Littlewood and Johnston, 1995; Barker and Blair, 1996; Morgan et al., 2003) and is designated herein as the 'benchmark topology'.

Between-partition-differences were assessed with partitioned Bremer support (Baker and DeSalle, 1997). These and Bremer support values (Bremer, 1994) were each calculated using TreeRot v. 2.0 (Sorenson, M.D., 1999, Boston University, Boston, MA) to generate commands for PAUP* and were executed with 100 repetitions. Partitioned Bremer support (Baker and DeSalle, 1997; Baker et al., 1998, 2001) assesses the extent to which a particular data set (each of the mt genes) contributes to the resolution of each node. The partitioned Bremer support was rescaled in order to be comparable between genes, and was expressed as how much longer (as a percentage) the node is without the optimal clade. Permutation tail probability (PTP) distances were calculated in PAUP* for all resultant topologies, in order to test whether the topologies were significantly different. The topologydependent cladistic permutation tail probability (T-PTP) test, as implemented in PAUP*, was used to compare the resultant topologies to the benchmark topology. An incongruence length difference (ILD) test (Farris et al., 1995), as implemented in PAUP*, was used to evaluate the null hypothesis that the characters that make up data partitions are drawn at random from a single population of characters, a single phylogeny and a single set of evolutionary processes (Farris et al., 1995; Hipp et al., 2004). The test is sensitive to between-partition differences in among-site variation (Hipp et al., 2004) and the size of the data partitions being tested (Dowton and Austin, 2002). Therefore, to avoid these problems, all phylogenetically uninformative characters were removed from the dataset (cf. Lee, 2001).

\subsection{Sliding window analysis to detect regions of high sequence variability}

In order to study the distribution of variation along the $\mathrm{mt}$ genome and to detect regions of highest variability, two pairs of closely related species were used: $S$. malayensis and $S$. mekongi ( $9 \%$ p-distance), and $S$. spindale and S. haematobium ( $29 \%$ p-distance). Pairwise comparisons of closely related species are less likely to reveal convergent similarities (incorrectly identified invariant positions) at third base positions in codons than comparisons between more distantly related taxa. A sliding window analysis, using DnaSP (Rokas et al., 2003), was employed for pairwise comparisons to detect variable nucleotide sites; DnaSP cannot analyse gaps as 
a fifth state, but excludes gapped sites. Sliding window analyses were performed with window/step sizes of 300/10, 24/3 and 1/1. Results were evaluated with Microsoft Excel according to requirements (e.g., size, proportion of variable sites) for particular molecular markers. Sliding window analyses were also conducted to compare intraspecific sequence polymorphisms using the dataset of Morgan et al. (2005). Correlation and regression analyses were conducted using SPSS v. 13.0 (SPSS, 2004). Finally, the position of the coxl barcode, as defined by the "Barcoding of Life" consortium (http://www.barcodinglife.com), was plotted on the sliding windows to compare and contrast sequence variability in this region against the entire $\mathrm{mt}$ genomes.

\subsection{Primer design}

The selection of molecular markers is principally dictated by a set of methodological constraints. For example, regions useful for species identification need to be bordered by regions of high sequence conservation, so that PCRbased methods can rely on a limited set of primers, and the length of resultant PCR products may need to fall within a particular size range, facilitating subsequent sequence or single-strand conformation polymorphism (SSCP) analysis. This is typically $300-600 \mathrm{bp}$ in molecular ecological studies (cf. DeSalle and Schierwater, 1998). The alignment of $S$. malayensis and $S$. mekongi was used as a basis for primer design in order to demonstrate the principle of sliding window analysis in identifying suitable regions for PCR-based studies. Although this alignment was incomplete, it offered the chance to compare the two most closely related taxa in order to identify regions of high nucleotide variability. Sliding window analyses of $300 \mathrm{bp}$ were run to indicate the most variable regions, whereas a window size of $20 \mathrm{bp}$ was used to identify the relatively conserved regions for primer design. By doing so, PCR primers were placed as efficiently as possible; i.e., capturing many variable positions in a short stretch. Primers were designed using Primer3 (Rozen and Skaletsky, 2000) and tested in silico on the $S$. japonicum $\mathrm{mt}$ genome using MacVector $^{\circledR} 7.2 .3$ (Accelrys). These same primer pairs were then tested against genomic DNA from $S$. japonicum, thus verifying their potential utility across species of southeast (SE) Asian schistosomes. DNA extracts from male worms were kindly provided by Dr David Johnston (NHM). The PCR was performed in a volume of $25 \mu 1$ using Ready-togo PCR Beads (Amersham Pharmacia Biotech) each containing 1.5 U DNA Taq Polymerase, $10 \mathrm{mM}$ Tris- $\mathrm{HCl}$ (pH 9), $50 \mathrm{mM} \mathrm{KCl}, 1.5 \mathrm{mM} \mathrm{MgCl}_{2}, 200 \mu \mathrm{M}$ of each deoxyribonucleotide triphosphate (dNTP) and stabilizers including BSA, $0.4 \mu \mathrm{M}$ of each primer and $2 \mu \mathrm{l}$ of DNA $(\sim 10 \mathrm{ng})$. Cycling was performed in a Perkin Elmer 9600 Thermal Cycler as follows: denaturation at $94{ }^{\circ} \mathrm{C}$ for $2 \mathrm{~min}$, followed by 40 cycles of $1 \mathrm{~min}$ at $94^{\circ} \mathrm{C}, 30 \mathrm{~s}$ at $52{ }^{\circ} \mathrm{C}, 2 \mathrm{~min}$ at $72{ }^{\circ} \mathrm{C}$; followed by a final extension of 7 min at $72^{\circ} \mathrm{C}$. Amplicons were detected by loading $3 \mu 1$ of each PCR on 1\% TAE (Tris-acetate-EDTA) agarose gels.

\section{Results}

\subsection{Phylogenetic information content}

Results from each of the three criteria to determine phylogenetic information content are considered.

\subsubsection{Length variance and information content}

The $\mathrm{mt}$ genomes used in this study were $14-15 \mathrm{~kb}$ long, excluding the control region, with $\sim 12 \mathrm{~kb}$ unambiguously alignable. The base composition was heavily skewed $(\mathrm{A}=23 \%, \mathrm{C}=8 \%, \mathrm{G}=23 \%$ and $\mathrm{T}=46 \%)$ and homogeneous for the ingroup species when the proteincoding genes alone were considered. The length and length variance of individual genes, as determined for nucleotides, is shown in Table 1. The relative lengths of $\mathrm{mt}$ genes were essentially the same among flatworm $\mathrm{mt}$ genes except in the cases of coxl and cox2, which were the most variable in length; for coxl, gene length varied between 1494 and $1830 \mathrm{bp}$ amongst digeneans, and cox2 differed by more than $100 \mathrm{bp}$ in length between $S$. mansoni and $S$. mekongi. Length variance has implications in phylogenetic analysis when dealing with indels in alignments, and in seeking unique diagnostic markers that incorporate or make use of indel signatures. The gene sequence datasets, excluding tRNAs, contained $45 \%$ phylogenetically informative characters (coded as nucleotides and including ribosomal genes, under the principles of parsimony). When conceptually translated as amino acids (protein-coding genes only), $54 \%$ of the characters were phylogenetically informative. Maximum and minimum proportions of phylogenetically informative positions with nucleotides were $57 \%$ for $n a d 5$ and $30 \%$ for the $r r n S$ datasets, respectively. For proteins, the maximum was $71 \%$ informative characters in nad $4 L$ and the minimum was $25 \%$ in coxl (Table 2).

\subsubsection{Phylogenetic analysis and topological congruence}

The resulting topologies from BI, with posterior probability support values for all analysed datasets, are listed in Table 3. Almost identical results and relative levels of support were obtained with MP; differences are shown in the table. Support values were generally very high, with the most frequent posterior probability of $100 \%$, reflecting general agreement with the benchmark phylogeny. Less congruent topologies generally had lower support values. The partitioned Bremer support showed that the optimal tree for a partition without the node from the hypothesis was $1-5 \%$ longer in tree length (data not shown). Most support was given to the outgroup clade $F$. hepatica $+P$. westermani. The least support was given to the $S$. spindale $+S$. haematobium clade, where there were a few negative values, indicating that another topology had a more optimal solution for those particular datasets. 
Table 1

Properties of the mitochondrial genes

\begin{tabular}{|c|c|c|c|c|c|c|c|c|c|c|c|c|c|}
\hline & \multicolumn{12}{|c|}{ Length of individual genes (bp) } & \multirow[t]{2}{*}{ No. amino acids } \\
\hline & atp6 & $\operatorname{cox} 1$ & $\operatorname{cox} 2$ & $\cos 3$ & $c o b$ & nadl & $\operatorname{nad} 2$ & nad3 & nad4 & $\operatorname{nad} 4 \mathrm{~L}$ & nad5 & nad6 & \\
\hline Fasciola hepatica & 516 & 1533 & 603 & 642 & 1113 & 903 & 867 & 357 & 1272 & 273 & 1569 & 453 & 3367 \\
\hline Paragonimus westermani & 513 & 1494 & 600 & 645 & 1119 & 891 & 867 & 357 & 1206 & 258 & 1584 & 453 & 3329 \\
\hline Schistosoma haematobium & 525 & 1806 & 597 & 666 & 1116 & 882 & 840 & 369 & 1266 & 261 & 1584 & 474 & 3462 \\
\hline Schistosoma japonicum & 519 & 1644 & 609 & 650 & 1116 & 891 & 855 & 360 & 1275 & 264 & 1587 & 459 & 3410 \\
\hline Schistosoma malayensis & 522 & $\underline{1209}$ & $\mathrm{a}$ & 651 & 1119 & 894 & 852 & 363 & 1272 & 264 & $\underline{999}$ & a & 1979 \\
\hline Schistosoma mansoni & 522 & 1830 & 594 & 654 & 1095 & 891 & 840 & 363 & 1260 & 261 & 1584 & 450 & 3448 \\
\hline Schistosoma mekongi & 522 & 1650 & 699 & 651 & 1119 & 888 & 852 & 363 & 1272 & 264 & 1593 & 462 & 3445 \\
\hline Schistosoma spindale & 522 & 1764 & 642 & 666 & 1095 & 876 & 840 & 369 & 1263 & 255 & 1587 & 468 & 3449 \\
\hline Average length (bp) & 520 & 1674 & 621 & 653 & 1112 & 890 & 852 & 363 & 1261 & 263 & 1584 & 460 & \\
\hline Length variance $^{\mathrm{b}}$ & 15 & 17,269 & 1456 & 77 & 108 & 64 & 127 & 22 & 516 & 28 & 54 & 77 & \\
\hline Rescaled variance ${ }^{c}$ & 0.0 & 10.3 & 2.3 & 0.1 & 0.1 & 0.1 & 0.1 & 0.1 & 0.4 & 0.1 & 0.0 & 0.2 & \\
\hline
\end{tabular}

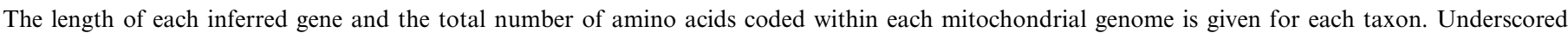
figures represent partial genes and were not used to calculate the average gene length or length variance.

a Indicates no data available.

b Length variance is a measure of how much the length of each sample deviates from the mean.

c Rescaled variance is the variance/bp.

Table 2

Information content for each mitochondrial gene calculated for all taxa

\begin{tabular}{|c|c|c|c|c|c|c|c|c|c|c|c|c|c|c|}
\hline & \multicolumn{14}{|l|}{ Gene } \\
\hline & atp6 & $\operatorname{cox} 1$ & $\cos 2$ & $\cos 3$ & $c o b$ & nadl & nad2 & $\operatorname{nad} 3$ & nad4 & $\operatorname{nad} 4 L$ & nad5 & nad6 & $r r n S$ & $r r n L$ \\
\hline \multicolumn{15}{|l|}{ Nucleotides } \\
\hline Number of characters & 528 & 1524 & 597 & 651 & 1104 & 891 & 882 & 369 & 1275 & 258 & 1617 & 471 & 782 & 1068 \\
\hline Constant characters & 144 & 757 & 191 & 147 & 405 & 278 & 212 & 106 & 279 & 67 & 363 & 104 & 332 & 399 \\
\hline Variable characters & 384 & 767 & 406 & 504 & 699 & 613 & 670 & 263 & 996 & 191 & 1254 & 367 & 450 & 669 \\
\hline Variable uninformative & 95 & 291 & 137 & 149 & 195 & 160 & 223 & 71 & 286 & 46 & 334 & 109 & 219 & 301 \\
\hline Informative characters & 289 & 476 & 269 & 355 & 504 & 453 & 447 & 192 & 710 & 145 & 920 & 258 & 231 & 368 \\
\hline$\%$ variable & $73 \%$ & $50 \%$ & $68 \%$ & $77 \%$ & $63 \%$ & $69 \%$ & $76 \%$ & $71 \%$ & $78 \%$ & $74 \%$ & $78 \%$ & $78 \%$ & $58 \%$ & $63 \%$ \\
\hline$\%$ informative & $55 \%$ & $31 \%$ & $45 \%$ & $55 \%$ & $46 \%$ & $51 \%$ & $51 \%$ & $52 \%$ & $56 \%$ & $56 \%$ & $57 \%$ & $55 \%$ & $30 \%$ & $34 \%$ \\
\hline Phylogenetic accuracy & High & High & None & High & Low & High & High & Low & High & Low & Low & None & None & None \\
\hline \multicolumn{15}{|l|}{ Amino acids } \\
\hline Number of characters & 176 & 508 & 199 & 217 & 364 & 297 & 294 & 123 & 425 & 86 & 539 & 157 & & \\
\hline Constant characters & 39 & 292 & 60 & 34 & 125 & 77 & 49 & 32 & 76 & 13 & 101 & 24 & & \\
\hline Variable characters & 137 & 216 & 139 & 183 & 239 & 220 & 245 & 91 & 349 & 73 & 438 & 133 & & \\
\hline Variable uninformative & 36 & 88 & 68 & 51 & 61 & 54 & 77 & 17 & 96 & 12 & 121 & 44 & & \\
\hline Informative characters & 101 & 128 & 71 & 132 & 178 & 166 & 168 & 74 & 253 & 61 & 317 & 89 & & \\
\hline$\%$ variable & $78 \%$ & $43 \%$ & $70 \%$ & $84 \%$ & $66 \%$ & $74 \%$ & $83 \%$ & $74 \%$ & $82 \%$ & $85 \%$ & $81 \%$ & $85 \%$ & & \\
\hline$\%$ informative & $57 \%$ & $25 \%$ & $36 \%$ & $61 \%$ & $49 \%$ & $56 \%$ & $57 \%$ & $60 \%$ & $60 \%$ & $71 \%$ & $59 \%$ & $57 \%$ & & \\
\hline Phylogenetic accuracy & None & High & None & High & Low & High & Low & High & High & Low & Low & None & & \\
\hline
\end{tabular}

Phylogenetic accuracy is judged on the basis of T-PTP test results comparing individual gene topologies from different analytical methods against the benchmark hypothesis of Lockyer et al. (2003b); see text for further details.

\subsubsection{Signal and noise in the molecular data}

The partition homogeneity test (ILD) showed that the various genes, using the concatenated protein dataset, did not contain conflicting phylogenetic signal $(P=0.48)$ The same was true in the rRNA sequence dataset $(P=0.93)$, suggesting that both datasets were homogeneous. In contrast, the tRNAs were not found to be homogeneous $(P=0.01)$. Suboptimal phylogenies were ranked as low, with the aid of the T-PTP test results; phylogenies entirely incongruent with the benchmark were scored as having no phylogenetic accuracy (data not shown). Table 4 provides a summary of the phylogenetic utility of the $\mathrm{mt}$ genes based on length variance, information content, nodal support and topological congruence.

\subsection{Comparison of pairwise alignments}

Two groups of schistosomes were chosen for sliding window analysis: a pair of closely related sister taxa (S. mekongi and S. malayensis; Fig. 2) and two more distantly related taxa but with the same gene order (S. haematobium and S. spindale; Fig. 6). The alignment of $S$. mekongi and $S$. malayensis (mekongi-malayensis) was $9598 \mathrm{bp}$ long, as the $S$. malayensis sequence was incomplete. It contained $9.6 \%$ variable ungapped characters with the smallest gap between two variable characters being $1 \mathrm{bp}$ and the longest $80 \mathrm{bp}$. The uncorrected pairwise distance between this pair of taxa, protein-coding genes only, was $9 \%$. The alignment of $S$. haematobium and 
Table 3

Results of Bayesian inference (BI) and maximum parsimony (MP) analyses showing: (a) all partitions supported by analyses, (b) benchmark hypothesis of Lockyer et al. (2003) with bipartitions 1-5, (c) BI (posterior probability) and MP (\% bootstrap) nodal support values given to different nodes in analyses of partitioned datasets (genes) of both nucleotides (nuc) and amino acids (aa, of protein coding genes); RNA genes were analysed as nucleotides

\begin{tabular}{|c|c|c|c|c|c|c|c|c|c|c|c|c|c|}
\hline \multirow[t]{2}{*}{ (a) } & \multicolumn{12}{|c|}{ Bipartition (node) number } & \multirow[t]{2}{*}{ (b) } \\
\hline & 1 & 2 & 3 & 4 & 5 & 6 & 7 & 8 & 9 & 10 & 11 & 12 & \\
\hline Schistosoma spindale & - & + & + & - & - & + & - & - & + & + & + & - & Nodes $1-5$ \\
\hline Schistosoma haematobium & - & + & + & - & - & - & - & + & + & + & + & + & Fasciola \\
\hline Schistosoma mansoni & - & - & + & - & - & + & + & + & - & + & + & - & _ Paragonimus \\
\hline Schistosoma mekongi & - & - & - & + & + & - & + & - & + & + & + & + & 5.japonicum \\
\hline Schistosoma japonicum & - & - & - & - & + & - & - & - & + & - & - & + & (5) - malayensis \\
\hline S. malayensis & - & - & - & + & + & - & + & - & + & + & - & - & Ls. mekongi \\
\hline Fasciola & + & - & - & - & - & - & - & - & - & - & - & - & - S.mansoni \\
\hline Paragonimus & + & - & - & - & - & - & - & - & - & - & - & - & (3)/3 5 -spindale \\
\hline
\end{tabular}

Gene Data Bipartition number and nodal support (BI/MP)

Inclusiveness $(\%)$

\begin{tabular}{|c|c|c|c|c|c|c|c|c|c|c|c|c|c|c|}
\hline & & 1 & 2 & 3 & 4 & 5 & 6 & 7 & 8 & 9 & 10 & 11 & 12 & \\
\hline \multicolumn{15}{|l|}{ (c) } \\
\hline \multirow[t]{4}{*}{ atp6 } & nuc & 1.00 & 0.53 & 0.99 & 1.00 & 0.98 & & & & & & & & 90 \\
\hline & & 100 & 65 & 98 & 100 & 100 & & & & & & & & 93 \\
\hline & aa & 1.00 & & 1.00 & 1.00 & 1.00 & & & 0.77 & & & & & 95 \\
\hline & & 100 & & 90 & 100 & 99 & & & 58 & & & & & 89 \\
\hline \multirow[t]{4}{*}{$\operatorname{cox} 1$} & nuc & 1.00 & 0.92 & 0.73 & 1.00 & 1.00 & & & & & & & & 93 \\
\hline & & 100 & 95 & 92 & 100 & 100 & & & & & & & & 97 \\
\hline & aa & 1.00 & 1.00 & 1.00 & 1.00 & 1.00 & & & & & & & & 100 \\
\hline & & 100 & 94 & 96 & 100 & 98 & & & & & & & & 98 \\
\hline \multirow[t]{4}{*}{$\cos 2$} & nuc & 1.00 & & 1.00 & & & & & 0.52 & & & & 0.51 & 76 \\
\hline & & 100 & & 90 & & 55 & & & 41 & & & & & 72 \\
\hline & aa & 1.00 & & 1.00 & & 0.99 & 0.80 & & & & & & & 95 \\
\hline & & 100 & & & & 91 & 45 & & & & & & 41 & 69 \\
\hline \multirow[t]{4}{*}{$\cos 3$} & nuc & 1.00 & 1.00 & 0.99 & 0.91 & 0.99 & & & & & & & & 98 \\
\hline & & 100 & 100 & 95 & 100 & 100 & & & & & & & & 99 \\
\hline & aa & 1.00 & 1.00 & 1.00 & 1.00 & 1.00 & & & & & & & & 100 \\
\hline & & 100 & 96 & 96 & 100 & 100 & & & & & & & & 98 \\
\hline \multirow[t]{4}{*}{$c y t b$} & nuc & 1.00 & & 1.00 & 1.00 & 0.95 & 0.99 & & & & & & & 99 \\
\hline & & 100 & 62 & 98 & 100 & 99 & & & & & & & & 92 \\
\hline & aa & 1.00 & 0.92 & 1.00 & 1.00 & 1.00 & & & & & & & & 98 \\
\hline & & 100 & 67 & 98 & 100 & 100 & & & & & & & & 93 \\
\hline \multirow[t]{4}{*}{ nadl } & nuc & 1.00 & 0.99 & 1.00 & 1.00 & 0.82 & & & & & & & & 96 \\
\hline & & 100 & 93 & 99 & 100 & 99 & & & & & & & & 98 \\
\hline & aa & 1.00 & 1.00 & 1.00 & 1.00 & 1.00 & & & & & & & & 100 \\
\hline & & 100 & 67 & 99 & 100 & 96 & & & & & & & & 92 \\
\hline \multirow[t]{4}{*}{$\operatorname{nad} 2$} & nuc & 1.00 & 0.83 & 1.00 & 0.99 & 0.79 & & & & & & & & 92 \\
\hline & & 100 & 97 & 100 & 100 & 100 & & & & & & & & 99 \\
\hline & aa & 1.00 & 0.83 & 1.00 & 1.00 & 1.00 & & & & & & & & 98 \\
\hline & & 98 & & 94 & 100 & 98 & & & 59 & & & & & 90 \\
\hline \multirow[t]{4}{*}{ nad3 } & nuc & 1.00 & 0.91 & 1.00 & 0.85 & & & & & & 0.67 & & & 90 \\
\hline & & 100 & 81 & 100 & 100 & 89 & & & & & & & & 94 \\
\hline & aa & 1.00 & 0.91 & 1.00 & 0.90 & 0.68 & & & & & & & & 91 \\
\hline & & 100 & 78 & 95 & 95 & 99 & & & & & & & & 93 \\
\hline \multirow[t]{4}{*}{ nad4 } & nuc & 1.00 & 0.97 & 1.00 & 1.00 & 0.99 & & & & & & & & 100 \\
\hline & & 100 & 98 & 98 & 100 & 100 & & & & & & & & 99 \\
\hline & aa & 1.00 & 0.99 & 1.00 & 1.00 & 1.00 & & & & & & & & 100 \\
\hline & & 100 & 74 & 97 & 100 & 100 & & & & & & & & 94 \\
\hline \multirow[t]{4}{*}{$\operatorname{nad} 4 L$} & nuc & 1.00 & 0.99 & & 0.52 & 0.97 & & & & 0.61 & & & & 82 \\
\hline & & 100 & 97 & 58 & 96 & 86 & & & & & & & & 87 \\
\hline & aa & 1.00 & 1.00 & 0.97 & 0.98 & 0.84 & & & & & & & & 96 \\
\hline & & 100 & 83 & 44 & 86 & 96 & & & & & & & & 82 \\
\hline
\end{tabular}




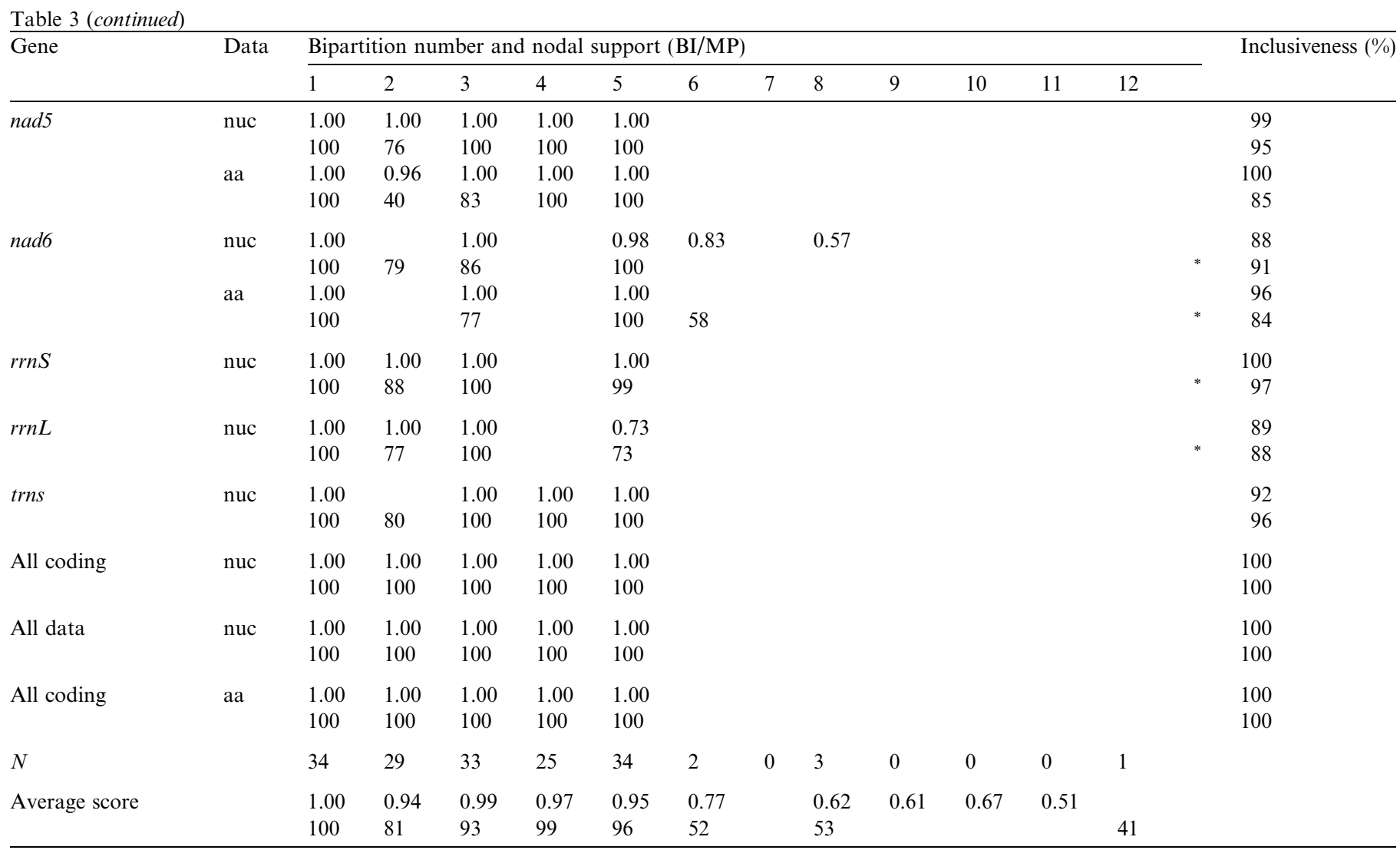

Bipartitions 1-5 are those nodes corresponding to the phylogenetic hypothesis of Lockyer et al. (2003). An asterisk at the end of a line indicates that data for Schistosoma malayensis was not available. Percent inclusiveness indicates how much of the topology is explained by the best-supported nodes. At the bottom of the table the number of occurrences of the node is given, along with the average score.

S. spindale (haematobium-spindale) was $17,456 \mathrm{bp}$ long and contained 3916 variable ungapped characters. The mean genetic distance between this pair of taxa was $29 \%$ (protein-coding genes only).

Between the pairs of alignments there were several changes in gene order (Le et al., 2000a). The longest conserved fragment includes nad5, cox3, cob, nad4L and nad4. A few features were common between the alignments of mekongi-malayensis and spindale-haematobium. One was that the $3^{\prime}$ end of coxl, encompassing the region chosen as a DNA barcode (Hebert et al., 2003b), was the most conserved longer region (Figs. 2 and 6). A distinct difference was that the very beginning of coxl had the highest nucleotide diversity in the spindale-haematobium alignment, but very low nucleotide diversity in the mekongimalayensis alignment. This might have been due to the gene rearrangement that moved coxl to a position adjoining the large non-coding region in $S$. spindale and $S$. haematobium. The beginning of coxl was unalignable for these taxa. Both pairwise alignments had greatest nucleotide diversity at the $3^{\prime}$ end of nad5. The profile of atp6 and nad 2 was similar, with three maxima and three minima of average nucleotide diversity. Genes nad4L and nad4 showed contrasting patterns of divergence; in the spindale-haematobium alignment it was most conserved in the middle, but in the mekongi- malayensis alignment, this middle region was the most variable. Generally, the divergence seemed to be highest towards the ends of a protein.

\subsection{Distribution and co-variation of divergence and polymorphisms over different scales}

The distribution of divergent sites between S. mekongi and $S$. malayensis is shown in Fig. 2. It was unevenly distributed, confirmed by frequency distributions of divergence (Fig. 3a and b) and plots of the distance between them (Fig. 4). The random distribution (grey bars) was generated in Excel (Microsoft) with the same number of divergent sites as in the original dataset. Fig. 4 shows that the majority of divergent sites were clustered together, with conserved stretches of up to $81 \mathrm{bp}$. Every third position contained more divergent sites, confirming that third codon positions evolve more rapidly.

In order to establish whether the distribution of divergent characters was conserved between different phylogenetic levels, we used the alignment of $S$. mekongi and $S$. malayensis, and the alignment of $S$. haematobium and $S$. spindale combined with the intraspecific data of S. mansoni from Morgan et al. (2005). This latter dataset consists of coxl, rrnL-rrnS, cytb-nad4L-nad4 and nad1. 
Table 4

Overview of phylogenetic utility of individual mitochondrial genes in providing sufficient signal and resolving accurately the benchmark topology of Lockyer et al. (2003b), with strong nodal support across and in relation to relative length of genes

\begin{tabular}{|c|c|c|}
\hline $\begin{array}{l}\text { Criteria for gene utility of } \\
\text { phylogenetic inference }\end{array}$ & Best & Worst \\
\hline 1. Data features & atp6 & $\operatorname{cox} 1$ \\
\hline \multirow{7}{*}{$\begin{array}{l}\text { Datasets that have the lowest amount } \\
\text { of length variance and the highest } \\
\text { information content have } \\
\text { been considered good }\end{array}$} & $\operatorname{cox} 3$ & $\operatorname{cox} 2$ \\
\hline & nad1 & nad4 \\
\hline & $\operatorname{nad} 2$ & $\operatorname{rrnL}$ \\
\hline & nad3 & $\operatorname{rrn} S$ \\
\hline & $\operatorname{nad} 4 L$ & \\
\hline & nad5 & \\
\hline & nad6 & \\
\hline 2. Support values, resolution & $\operatorname{cox} 1$ & $\operatorname{cox} 2$ \\
\hline \multirow{3}{*}{$\begin{array}{l}\text { Datasets with high bootstrap support and } \\
\text { posterior probabilities have been considered } \\
\text { good. Several datasets not listed have good } \\
\text { support values in either, but not in both }\end{array}$} & $\cos 3$ & $\operatorname{nad} 4 \mathrm{~L}$ \\
\hline & nad4 & $\operatorname{rrnL}$ \\
\hline & $\operatorname{rrn} S$ & \\
\hline 3. Topological congruence ${ }^{\mathrm{a}}$ & $\operatorname{cox} 1$ & $\operatorname{cox} 2$ \\
\hline \multirow{4}{*}{$\begin{array}{l}\text { The best genes give a phylogenetic signal } \\
\text { that is congruent to the benchmark } \\
\text { hypothesis no matter which method } \\
\text { is used }\end{array}$} & $\cos 3$ & nad6 \\
\hline & nadl & $\operatorname{rrnL}$ \\
\hline & $\operatorname{nad4}$ & $\operatorname{rrn} S$ \\
\hline & nad5 & \\
\hline
\end{tabular}

${ }^{\text {a }}$ With reference to benchmark hypothesis of Lockyer et al. (2003b).

For each of these gene fragments, we tested the correlation between intraspecific and interspecific variation (Pearson's correlation, window size of $24 \mathrm{bp}$ and step size 3). Table 5 shows that the level of polymorphism in $S$. mansoni was always correlated with the level of divergence between $S$. spindale and $S$. haematobium, but only correlated with the divergence in $S$. malayensis and $S$. mekongi for nad4 and $r r n L-r r n S$. The levels of divergence in the pairs $S$. malayensis and S. mekongi, and S. spindale and S. haematobium were always correlated except for the nadl dataset. Applying a sliding window of $1 \mathrm{bp}$ and step size 1 resulted in positive correlations between all comparisons. This is also shown in Fig. 5a and $\mathrm{b}$ where the average nucleotide diversity $(\pi)$ among the three groups of sequences is plotted for the nadl and rrnL-rrnS datasets. Thus, if there is interspecific variation at a particular site there is also likely to be intraspecific variation at that site.

\subsection{Sliding window analysis and the identification of potential population markers}

Fig. 3 shows the frequency distribution of variable positions in any stretch of $300 \mathrm{bp}$ in the $S$. mekongi and $S$. malayensis alignment (black bars). The randomly generated dataset (grey bars) had a normal distribution whereas the variation in the real dataset appeared to be non-randomly distributed. Also, the random dataset had a lower maximum number of variable sites per $300 \mathrm{bp}$ than the real dataset (41 compared with a maximum of 52 sites). A $300 \mathrm{bp}$ sequence in the $S$. mekongi and $S$. malayensis alignment contained between 12 and 52 nucleotide changes (see Fig. 3). The sliding window analysis of the nucleotide diversity is shown in Fig. 2 (window size 300; step size 10). Using this alignment and sliding window results, PCR primers were designed in flanking sequences to allow the capture of as much of the sequence variability as possible. The regions that these primers amplify make up $20 \%$ of the total alignment, but contain $27 \%$ of the total number of nucleotide changes (Table 6). These primers were designed for $S$. mekongi and $S$. malayensis and should be applicable to species closely related to them; they were tested successfully using genomic DNA from $S$. japonicum (Fig. 7).

\section{Discussion}

With complete mt genomes available for a number of closely related species, we can test empirically the phylogenetic utility of individual genes and determine regions of the genomes that contain the greatest interspecific variation for ecological and diagnostic markers. By doing so, we can make optimal use of $\mathrm{mt}$ genomes. The utility of existing $\mathrm{mt}$ markers can also be assessed in the context of entire genomes through comparisons of sequence variation within and between species. In this way, existing primers (and gene regions) can be assessed and new primers can be designed and optimised, prior to extensive sampling. We present a comparative mitogenomic assessment of available data from Schistosoma, but the general methodology can be applied to other organisms.

The simplest criterion to judge the phylogenetic utility of any individual gene includes a determination of whether the gene recovers the "true phylogeny", with a measurement as to how robust that recovered phylogeny is. The "true phylogeny" is rarely available. For this study, genes yielding topologies identical to the benchmark hypothesis of Lockyer et al. (2003b) with full nodal support throughout the trees and full congruence among methods of analysis and between both nucleotide and amino acid data, were judged as most useful.

There are limits to the usefulness of the present dataset; e.g., it is an incomplete clade with only six ingroup taxa, providing 945 distinct tree topologies (Felsenstein, 1982). In spite of this low level of sampling, both closely related and less closely related species are included; hence no particular level of the phylogeny was excluded. Also, genes were used as units to compare their usefulness for phylogenetic reconstruction, for convenience and because gene order changes between the African-Indian and SE Asian clades obscure base positional homology in longer alignments spanning genes that have moved. Further studies with longer fragments of mtDNA, spanning different gene boundaries are possible. However, researchers are 


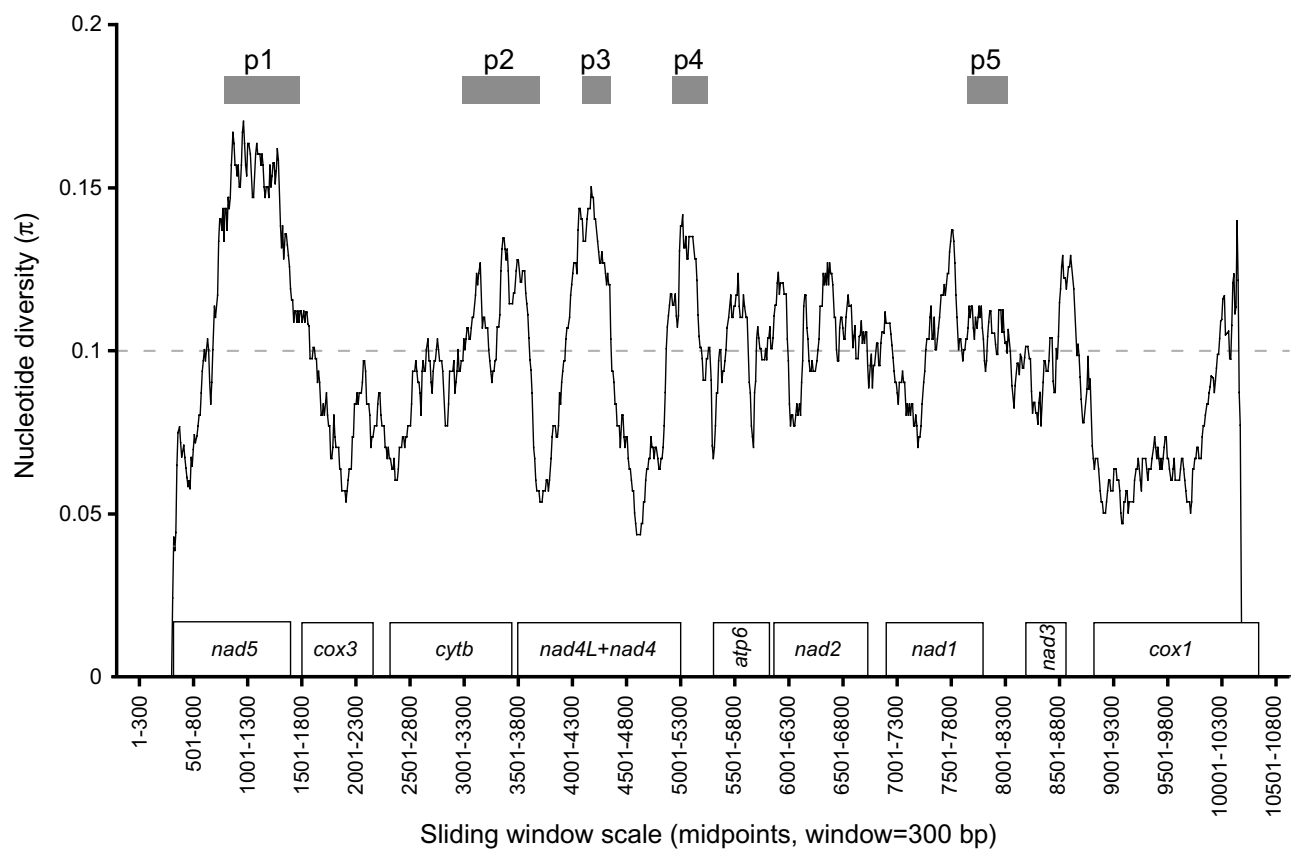

Fig. 2. Sliding window analyses of the alignment between Schistosoma mekongi and Schistosoma malayensis. The line shows the value of nucleotide diversity $(\pi)$ in a sliding window analysis of window size $300 \mathrm{bp}$ with step size 10 , the value is inserted at its mid-point. The horizontal grey dashed line is a grid-line for reference. Gene boundaries are indicated; nad $4 L$ and nad 4 are overlapping. Grey boxes indicate the fragments amplified by five primer pairs (p1-p5) designed from this alignment (see Table 6 and Fig. 7).

a

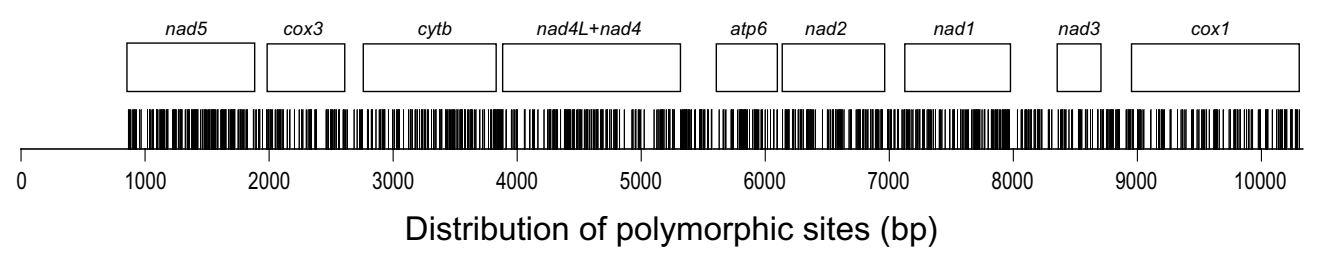

b

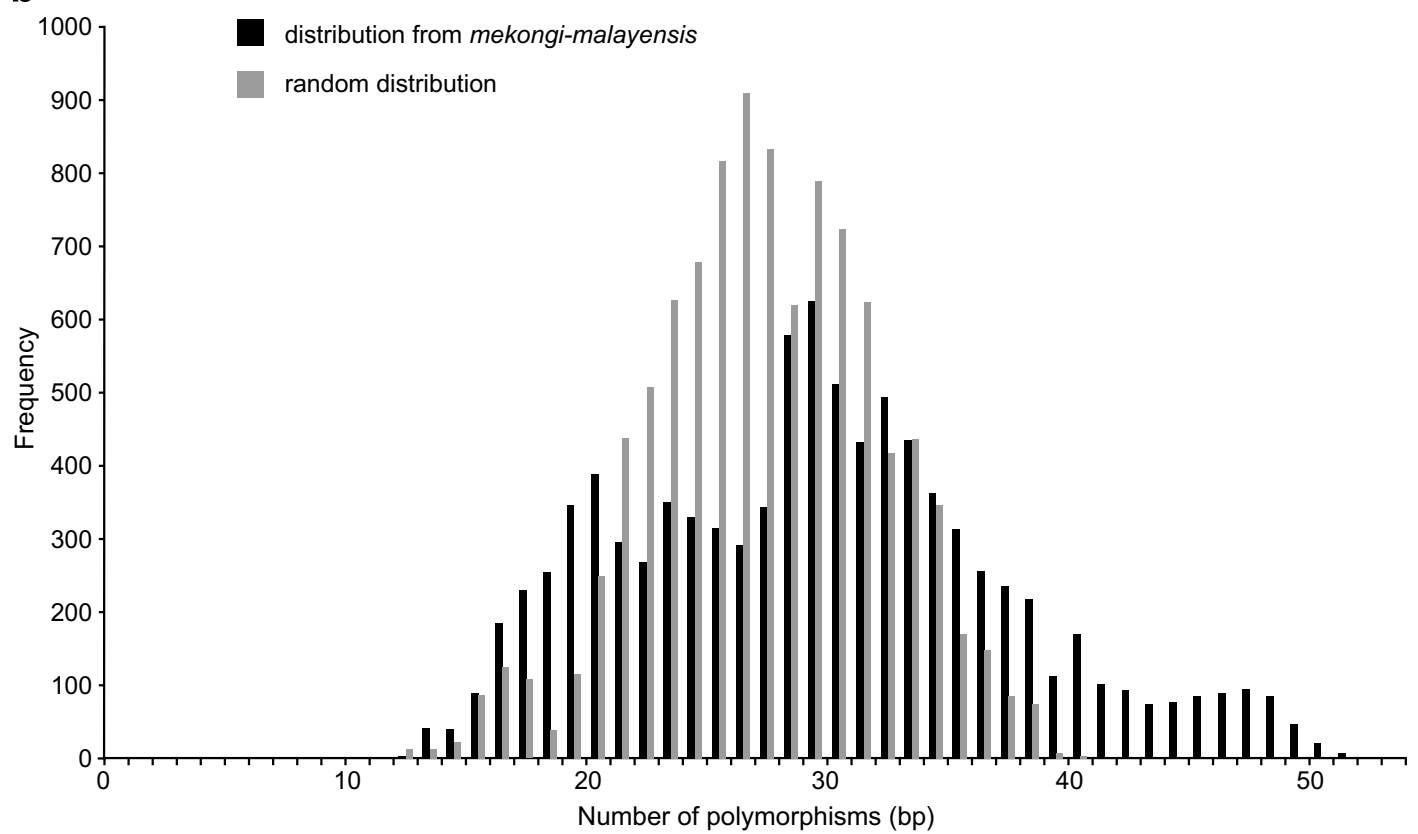

Fig. 3. (a) Distribution of polymorphic sites in the alignment of Schistosoma mekongi and Schistosoma malayensis using the same dataset as in Fig. 2. Each black bar is a polymorphism; polymorphisms were calculated by DnaSP and do not include gaps in the alignment. (b) Frequency distribution of the number of polymorphisms ( $x$-axis [bp]) in each possible region of $300 \mathrm{bp}$, along the alignment of the whole pairwise mitochondrial sequence of $S$. mekongi and $S$. malayensis; black bars show the real distribution, and grey bars are from a random distribution. 


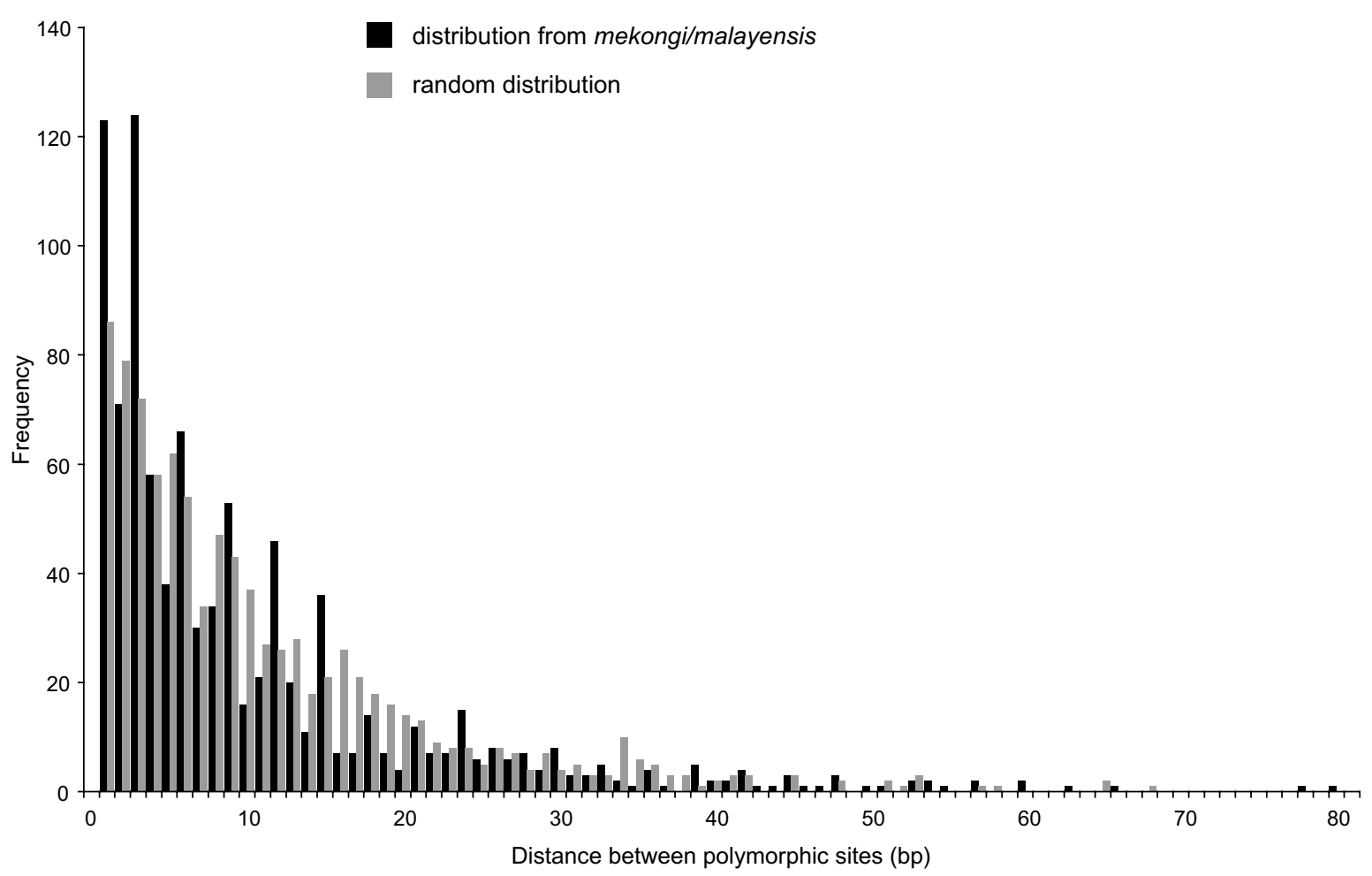

Fig. 4. Frequency distribution of distance between polymorphic sites in the Schistosoma mekongi and Schistosoma malayensis alignment (black bars), and values from a random distribution (grey).

Table 5

Summary of results of sliding window analyses, correlating intraspecific (Schistosoma mansoni) and interspecific variation

\begin{tabular}{lrlll}
\hline Gene & $\begin{array}{l}\text { Sliding window } \\
\text { length_step size (bp) }\end{array}$ & $\begin{array}{l}\text { Level of polymorphism }(\pi) \text { within } \\
\text { S. mansoni correlated with divergence }(\pi) \\
\text { between : }\end{array}$ \\
\cline { 3 - 5 } & & $\begin{array}{l}\text { spindale- } \\
\text { haematobium }\end{array}$ & $\begin{array}{l}\text { malayensis- mekongi } \\
\text { mekongi- }\end{array}$ & japonicum \\
\hline cox1 & $24 \_3$ & $0.216^{* *}$ & -0.130 & 0.138 \\
& $1 \_1$ & $0.167^{* *}$ & $0.119^{* *}$ & 0.014 \\
nad4 & $24 \_3$ & $0.249^{* *}$ & $0.269^{* *}$ & n.a. \\
& $1 \_1$ & $0.086^{*}$ & $0.090^{* *}$ & n.a. \\
$r r n S$ - & $24 \_3$ & $0.480^{* *}$ & n.a. & $0.555^{* *}$ \\
$r r n L$ & $1 \_1$ & $0.222^{* *}$ & n.a. & $0.152^{* *}$ \\
nad1 & $24 \_3$ & $0.462^{* *}$ & 0.022 & n.a. \\
& $1 \_1$ & $0.093^{*}$ & 0.070 & n.a. \\
\hline
\end{tabular}

Note: coxl in the malayensis-mekongi alignment was not complete. n.a. data not available due to partial Schistosoma malayensis sequence. ${ }^{*} P<0.05$.

** $P<0.001$.

primarily interested in amplifying and targeting specific genes or gene fragments; spanning gene boundaries is not of primary interest unless genes of interest are adjoining and can be amplified together.

Taking the topology of Lockyer et al. (2003b) as a benchmark, two genes were shown to be unsuitable as phylogenetic markers: cox2 and nad6. Both of these genes resolved phylogenies that were inconsistent with the benchmark, and with each other, no matter which method of analysis was used. The value of these genes for constructing phylogenies of schistosomes is deemed low. In contrast, genes nad1, nad4, nad5, coxl and cox3 gave results that are consistent with the hypothesis, no matter which method was used and whether data were treated as nucleotides or amino acids (Tables 3 and 4). Their value for phylogenetic analyses in schistosomes is therefore considered to be high. Other protein-coding genes gave results that were inconsistent, depending on which method was used. However, longer genes generally contain more variable characters with proportionally more signal, and hence offer better resolution than shorter ones. Genes comprising more than $1000 \mathrm{bp}$ gave an unambiguous phylogenetic signal. Comparing all individual gene datasets, they are congruent in most cases and resolve the expected phylogeny (Table 3). As a function of size of gene, lowest length variance and highest information content, the genes predicted to be best include cox3, nadl and nad5. Amongst the preferred genes, $\operatorname{cox} 1$, $\operatorname{cox} 3$ and nad4 resolved benchmark trees with consistently high nodal support throughout. There is a clear divergence between the SE Asian schistosome species and the other taxa, with slightly less nodal support within each clade. The relationships between $S$. spindale, S. haematobi$u m$ and $S$. mansoni are the least resolved, where several genes give an alternative to the most common solution ( $S$. mansoni ( $S$. spindale $+S$. haematobium)). Without a comparative analysis of $\mathrm{mt}$ genomes, it is unlikely that 

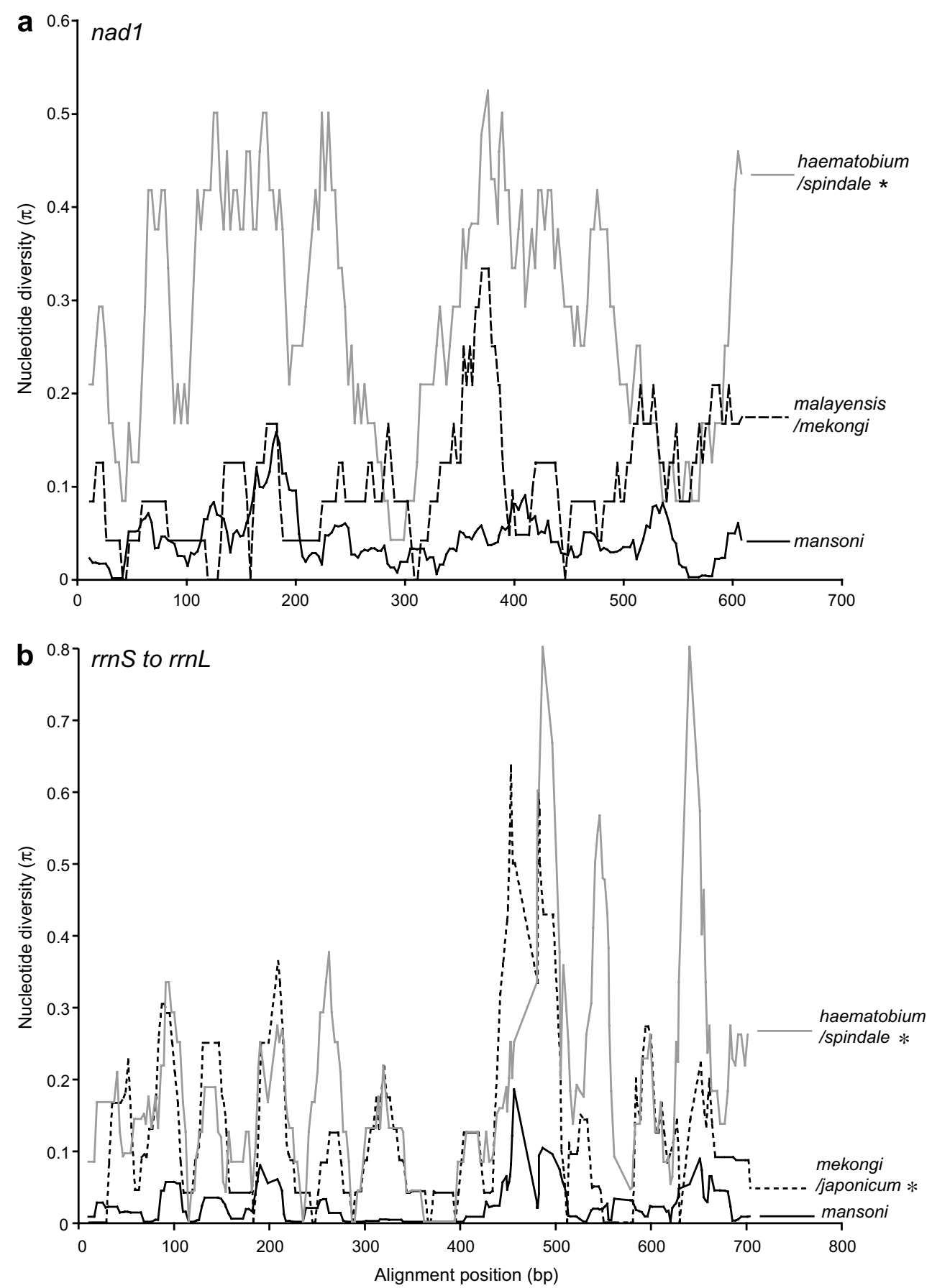

Fig. 5. Average nucleotide diversity ( $\pi$ ) in the nadl (a) and the rrnL-rrnS alignments (b) of Schistosoma mekongi + Schistosoma malayensis, Schistosoma haematobium + Schistosoma spindale, and Schistosoma mansoni (from Morgan et al., 2005) datasets; * indicates significant correlations of interspecific variation and intraspecific variation in $S$. mansoni (see Table 5).

genes such as $\operatorname{cox} 3$ or nad4 would be suggested as alternatives to the more commonly chosen coxl. Readily available primers for coxl and a wealth of comparative information for this gene allow for a potentially complacent approach to gene and primer selection. Moreover, poorly performing genes such as cox2 and nad6 could easily be chosen without recourse to preliminary phylogenetic analyses.

In a recent study assessing the phylogenetic performance of $\mathrm{mt}$ protein-coding genes from 11 neodermatan (parasitic platyhelminth) mt genomes (Hardman and Hardman,
2006), the authors concluded that any $4000 \mathrm{bp}$ of alignable $\mathrm{mt}$ sequence data would yield accurate phylogenetic estimates. All genes performed as well as randomly selected regions except nad2 and nad5, which performed significantly better and worse, respectively. This contrasts with the present study, which found nad5 was both accurate in resolving the benchmark phylogeny amongst schistosomes and provided a high level of information content (Table 4). Together with $\operatorname{cox} 3$, in the present study nad5 is considered to be a worthwhile gene for future sampling in phylogenetic 
Table 6

Primers identified as potential population markers among SE Asian schistosomes, from alignments of Schistosoma mekongi and Schistosoma malayensis mitochondrial genomes, capturing high levels of sequence variability; see Figs. 2 and 7

\begin{tabular}{|c|c|c|c|c|c|c|c|}
\hline Location & $\begin{array}{l}\text { Primer sets } \\
\text { (Fig. 2) }\end{array}$ & Forward $(\mathrm{F})$ Reverse $(\mathrm{R})$ primers (all $5^{\prime}$ to $\left.3^{\prime}\right)$ & Start $^{\mathrm{a}}$ & End $^{\mathrm{a}}$ & $\begin{array}{l}T_{\mathrm{m}} \\
\left({ }^{\circ} \mathrm{C}\right)\end{array}$ & $\begin{array}{l}\text { Product } \\
\text { (bp) }\end{array}$ & $\begin{array}{l}\% \text { divergent sites } \\
\text { in amplicon }\end{array}$ \\
\hline Middle to end of nad5 & p1 & $\begin{array}{l}\mathrm{F} \text { - GKTTATCTGGKTTTCCWTTTATGGG } \\
\mathrm{R} \text { - TGAGATCTCYTACTTGGAAAGAAAG }\end{array}$ & $\begin{array}{l}1067 \\
1759\end{array}$ & $\begin{array}{l}1091 \\
1735\end{array}$ & $\begin{array}{l}53.3 \\
50.0\end{array}$ & $\sim 693$ & 15 \\
\hline$c y t b-n a d 4 L$ & p2 & $\begin{array}{l}\mathrm{F} \text { - ATWAAGGATTTGTTTGYTTTTATG } \\
\mathrm{R} \text { - AYAAAGCCATCATCGAAATG }\end{array}$ & $\begin{array}{l}3244 \\
3926\end{array}$ & $\begin{array}{l}3267 \\
3907\end{array}$ & $\begin{array}{l}45.4 \\
47.0\end{array}$ & $\sim 683$ & 18 \\
\hline $\begin{array}{l}\text { End of nad5, through } \\
\operatorname{trn} G \text { to beginning } \\
\text { of } \cos 3\end{array}$ & p3 & $\begin{array}{l}\text { F - TTGATTWTTTGRTTKATATGTATA } \\
\text { R - TGAGATCTCYTACTTGGAAAGAA }\end{array}$ & $\begin{array}{l}1469 \\
1759\end{array}$ & $\begin{array}{l}1492 \\
1737\end{array}$ & $\begin{array}{l}48.7 \\
58.2\end{array}$ & $\sim 236$ & 15 \\
\hline nadl & $\mathrm{p} 4$ & $\begin{array}{l}\mathrm{F} \text { - TTTATTTGAGCRCGTGGTAC } \\
\mathrm{R} \text { - CGGAGTAACCTGCTTAGCA }\end{array}$ & $\begin{array}{l}7852 \\
8200\end{array}$ & $\begin{array}{l}7871 \\
8182\end{array}$ & $\begin{array}{l}45.4 \\
48.1\end{array}$ & $\sim 349$ & 10 \\
\hline $\begin{array}{l}\text { End of nad4, over } \operatorname{trn} Q \text { and } \operatorname{trn} F \\
\quad \text { and ending in } \operatorname{trn} M\end{array}$ & $\mathrm{p} 5$ & $\begin{array}{l}\mathrm{F} \text { - TGGWTTRGATAAATTWTTGTYTTGTA } \\
\mathrm{R} \text { - KTTTTMTTAACTTAATATCCACCTCT }\end{array}$ & $\begin{array}{l}5175 \\
5488\end{array}$ & $\begin{array}{l}5200 \\
5463\end{array}$ & $\begin{array}{l}49.1 \\
48.6\end{array}$ & $\sim 314$ & 14 \\
\hline
\end{tabular}

${ }^{a}$ Numbers refer to mitochondrial genome sequence of Schistosoma japonicum (NC_002544).

and molecular ecological studies. The taxonomic diversity of the study by Hardman and Hardman (2006) encompassed cyclophyllidean cestodes as well as schistosomes and other digeneans. As with other phylogenetic studies, the results from comparative mitogenomic analyses need to be considered with care and with reference to the questions being addressed, before embarking on large-scale sampling. Whilst nad5 may be appropriate for studies amongst schistosomes, it appears to have its limitations if more distantly related taxa are sampled. Denser sampling of $\mathrm{mt}$ genomes of Platyhelminthes will allow further studies of gene utility to be undertaken across different taxonomic ranges. If lengths of $\mathrm{mt}$ genomes are preferred over specific genes, then such studies will be necessary to assess the differences in $\mathrm{mt}$ gene order within and between flatworm groups; novel gene orders have now also been found amongst the Neodermata (Park et al., 2007). Gene order changes have a bearing on which genes or which gene regions can be amplified with universal primers to produce sufficiently long sequences ( $>4000 \mathrm{bp}$ ) for alignment and accurate phylogenetic analysis.

The distribution of divergence (differences between species) and polymorphism (differences within a species) over different scales are crucial for this study. The notion that "optimal" phylogenetic and population genetic markers can be constructed depends on two conditions: (i) an uneven distribution of informative characters, and (ii) a certain amount of conservatism in the distribution. Because of the functional constraints or absence of function for a particular region, we expect the distribution of variation to evolve in a predictable manner. Forces of positive and negative selection can affect evolutionary rates in entire proteins, regions of proteins or among individual base pairs and, in the case of $\mathrm{mt}$ genes, can affect the entire $\mathrm{mt}$ genome. If random mutations are sorted by selection in this way, one might expect to see a pattern of correlation between (a) nucleotide diversity in datasets of closely related taxa (b) inter- and intraspecific patterns of variation and (c) intraspecific patterns of variation between closely related species. These principles, although not always explicitly stated, are used quite often; for example, when a researcher uses PCR primers for the amplification of molecular markers that have given good results from one species, on a different, but closely related species.

A confounding issue when investigating correlation is that the co-variation can be measured on many different levels; in genes, predicted protein structures or codons, in regions of single to thousands of nucleotides. Which scale is investigated can dramatically affect the level of co-variation. Therefore, we used several different window and step sizes in the sliding window analyses $(1 / 1,9 / 3$, 24/3, 300/10; e.g., see Fig. 6); we would encourage this approach in future similar studies. The interspecific variation in the SE Asian schistosome clade was always correlated with the divergence in the African-Indian clade, except for nadl. When using a window and step size of $1 \mathrm{bp}$, the correlation in the latter region was also significant.

Using the mitochondrial dataset from Morgan et al. (2005) we took intraspecific gene sequences for $S$. mansoni $(n=99)$ and compared them with the corresponding alignment of $S$. spindale $+S$. haematobium and $S$. malayensis $+S$. mekongi (Fig. 5a and b). Fig. 6 indicates the gene/genome regions used in Morgan et al. (2005). For each region (coxl, rrnL-rrnS, cytb-nad4L-nad4 and nad1), the average nucleotide diversity $(\times 10)$ for the marker in the $S$. mansoni data is also shown. Separate sliding window analyses showed significant levels of correlation between the divergent and the polymorphic sites compared with the $S$. spindale and $S$. haematobium dataset. For $S$. malayensis and $S$. mekongi, a positive correlation was found in the cytb-nad4L-nad4 and the $r r n L-r r n S$ dataset; in nadl and coxl, significant values were only obtained with window size and step size 1. Schistosoma mansoni, $S$. haematobium and $S$. spindale all belong to the AfricanIndian clade, characterised by a different gene order 


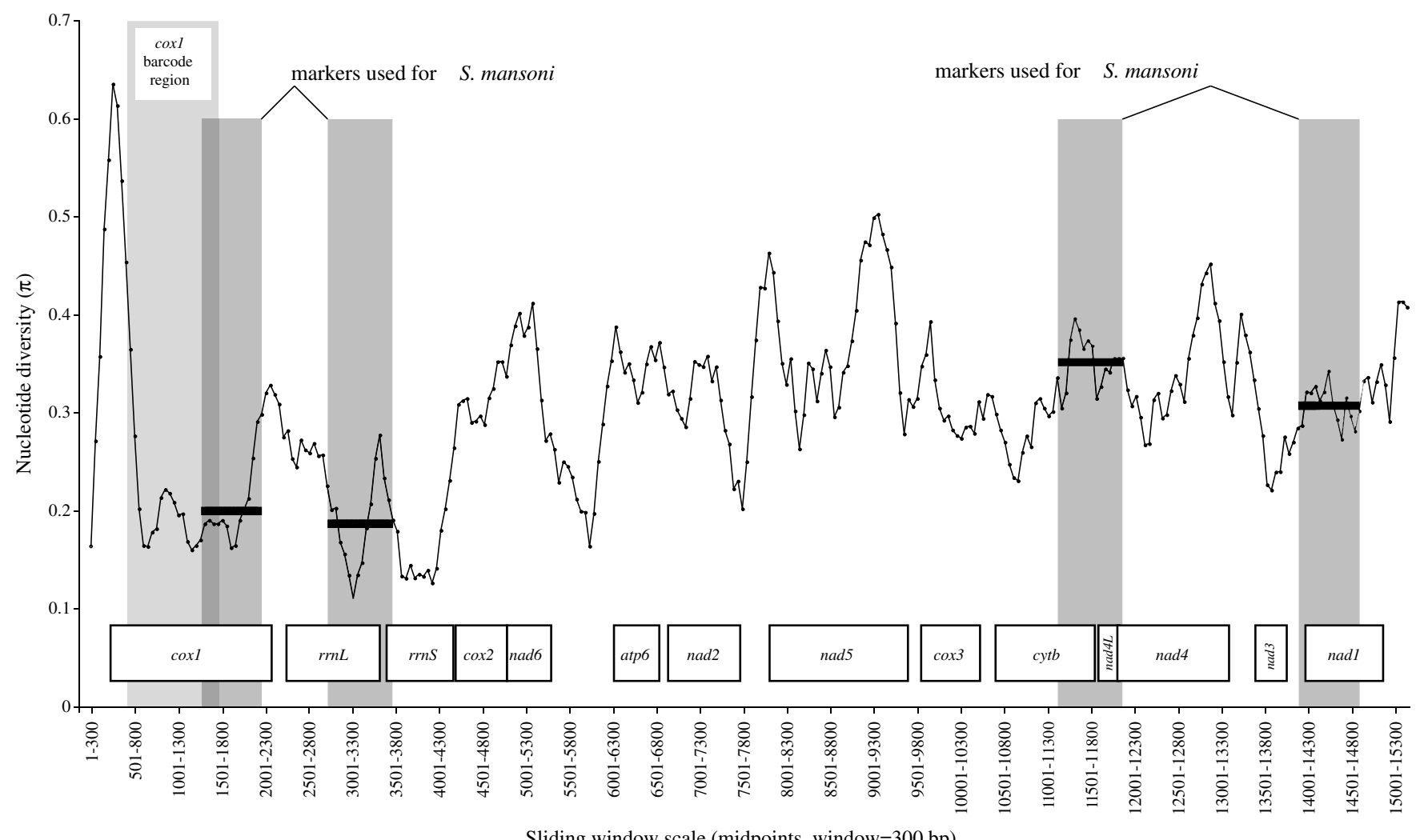

Fig. 6. Sliding window analysis (window size $300 \mathrm{bp}$, step size 50) of the alignment of the African-Indian species Schistosoma mansoni, Schistosoma haematobium and Schistosoma spindale. On the $y$-axis is the nucleotide diversity $(\pi)$ and on the $x$-axis the relative position on the mitochondrial genome (bp). The alignment starts at trnM and is annotated showing positions of protein-coding and ribosomal genes. Marker regions defined by Morgan et al. (2005) from their study on $S$. mansoni are shown, with black bars indicating the average nucleotide diversity for each fragment.

compared with the SE Asian clade ( $S$. mekongi and $S$. malayensis) and other neodermatan parasites. Thus, the correlation between polymorphism in the $S$. mansoni dataset and the African-Indian alignment is stronger than the correlation between the $S$. mansoni dataset and the SE Asian alignment. This finding may relate to the effect of phylogenetic constraint, or it might be conflated by the effect of a different gene order. As demonstrated, the level of divergence in the beginning of coxl was higher in the African-Indian species. Due to gene rearrangement, coxl is located adjacent to the non-coding region in the African-Indian species, but not in the SE Asian species. The gene flanking the non-coding region on the other side is nadl, which was the most variable gene in the study by Morgan et al. (2005). The rate of evolution of these genes might be linked with the non-coding region, which evolves at a different rate due to different selective pressures. Another explanation might be linked with the gene arrangement itself. According to Szczepanik et al. (2001), sequences in which gene orders have changed their positions recently are the most susceptible to mutation accumulation. The position of a gene with respect to the direction of replication fork movement is important; this position defines the duration that the heavy strand spends in the mutagenic single-strand state during replication (Szczepanik et al., 2001). Reyes et al. (1998) found a posi- tive correlation between the number of variable sites for a gene and its single-stranded state duration.

Thus, the selection on a gene, and therefore the evolutionary rate of nucleotide substitution, will depend on its position in the $\mathrm{mt}$ genome and on changes in $\mathrm{mt}$ gene order. Whether or not these issues have played a role in the present study, we can only speculate. However, if the species under study have the same genomic arrangement, the distribution of polymorphic and divergent characters is more likely to be correlated, such that an informed primer design is effective. Certainly, the correlation between polymorphism within a species (in this study $S$. mansoni) and divergence between species is more conserved over short phylogenetic distances.

Generally, population genetic markers need to be more variable than sequences used for phylogenetic studies. They need to amplify readily and give easily alignable and unambiguous sequence data. The $\mathrm{mt}$ genome has several desirable features, since it is rich in variable regions and it exists in multiple copies within cells, making it easy to amplify. We have developed and tested five sets of primers from the alignment of $S$. mekongi and $S$. malayensis (see Table 6). The primers are identical for both species, and attempt to capture as many of the variable sites between the species as possible. The primers were tested in silico against the $\mathrm{mt}$ genome sequence of $S$. japonicum using 
MacVector (Accelrys), and indeed worked extremely well against this template when tested experimentally (see Fig. 7). MacVector takes several features into account including self-duplexing, hairpins, specificity and mismatches. The primers are designed to amplify fragments of nadl, nad4, nad5, cox3 and some tRNA genes, capturing $20-27 \%$ of the variation present in the mt genome with less than $2300 \mathrm{bp}, \sim 16 \%$ of any SE Asian Schistosoma genome. These genes were predicted to be the most useful for phylogenetic reconstruction within the Schistosomatidae.

Only recently have microsatellites been isolated and used in schistosome research (Rodrigues et al., 2002; Srivastava et al., 2005; Sorensen et al., 2006). However, although a valuable resource, microsatellite markers are useful when studying very recent phenomena such as migration and bottlenecks. Few $\mathrm{mt}$ genes or gene regions have been used as population markers for Schistosoma. Although recognised as potentially useful from laboratory isolates of S. japonicum (see Sørensen et al., 1999), nadl has only been used in $S$. mansoni. Others have highlighted the potential utility of the polymorphic repeat element in the $\mathrm{mt}$ genome of $S$. mansoni (see Curtis and Minchella, 2000), and it has been used successfully in differentiating strains in snail hosts (Spotila et al., 1991; Minchella et al., 1994). However, Curtis and Minchella (2000) noted that there was a lot of heteroplasmy (noise) in this region, possibly related to a high mutation rate. The only study in which a combination of $\mathrm{mt}$ markers has been used with schistosomes is on $S$. mansoni by Morgan et al. (2005); these authors used partial fragments of coxl, rrnL-rrnS, cytb-nad4L-nad4 and nadl. However, as shown in Fig. 6, the $3^{\prime}$ ends of coxl and the rrnL-rrnS region have a low number of variable characters. Amplifying the $5^{\prime}$ end of coxl in combination with nad5 would substantially increase the number of variable characters per unit length. Thus, an informed primer design will be more cost-efficient, involve less sequencing and generate proportionally more information.

Finally, a comment on coxl as a DNA barcode in the context of schistosome research is warranted. Mitochondria are generally maternally inherited and this appears

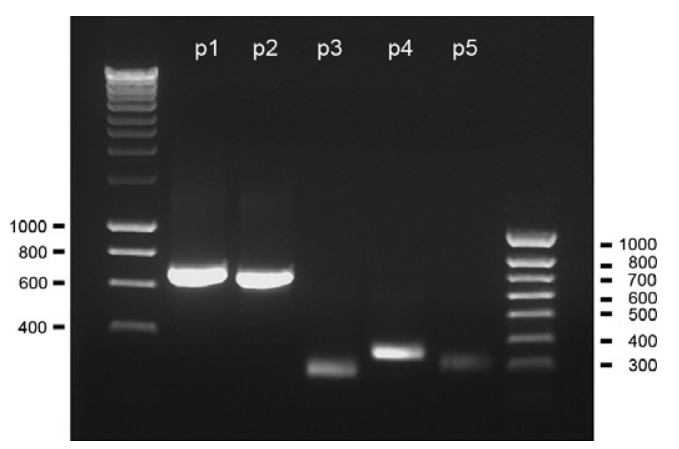

Fig. 7. Amplicons produced using primer sets p1-p5 with gDNA from Schistosoma japonicum, resolved by agarose gel electrophoresis; primer details and genes amplified given in Table 6 and indicated in Fig. 2. to be the case for flatworms (Johnston, 2006), although there may be evidence for paternal leakage according to Bieberich and Minchella (2001). As such, mt markers cannot be used to detect hybrids or hybridisation events except when used in conjunction with nuclear markers. Hybridisation within the genus Schistosoma is common (Webster et al., 2006) making species diagnosis with $\mathrm{mt}$ markers potentially problematic. Partial $\mathrm{mt}$ coxl, corresponding to the region chosen by the Consortium for the Barcoding of Life (CBOL; http://barcoding.si.edu/), has been characterised for almost all members of the genus Schistosoma (Webster et al., 2006). The only within-species study on $\mathrm{mt}$ gene utility in terms of resolving as many haplotypes as possible, is that of Morgan et al. (2005) for S. mansoni. Unfortunately, the coxl fragment they chose begins some 40 amino acids after the fragment promoted by the "Barcoding of Life" consortium. However, both from our study and that of Morgan et al. (2005), it is clear that nadl and the $c y t b-n a d 4 L$ fragment provide greater variation and resolving power than coxl, presumably by capturing considerably more nucleotide diversity. The present study provides additional advantages and disadvantages in considering coxl for species identification. A simple unrooted distance tree (not shown) differentiates individual species but with very short internodal and terminal branch lengths between members of the African-Indian species (a clade within which hybridisation is particularly common), suggesting the need for a more variable marker. In the current study, the coxl barcode region of the $\mathrm{mt}$ genome by no means encompasses the greatest molecular diversity or potential resolving power; it has the lowest number of phylogenetically informative characters. Therefore, given the availability of full $\mathrm{mt}$ genome sequences, we suggest cox3 and nad4. Full $\mathrm{mt}$ genome sequences allow the assessment of such preferred barcoding regions, prior to their widescale use.

In conclusion, using Lockyer et al. (2003b) as a "benchmark", this study has predicted that a single mt gene is sufficient to give a well-resolved, accurate phylogeny of the schistosomes. For accurate identification (sufficient variability) and a consistent phylogenetic signal (sufficient number of phylogenetically informative characters per total length), cox3 is the preferred gene, with high variability in characters, but not in length. Genes nadl, nad4, nad5 and coxl also give coherent topologies but they are also the longest genes. Of these, nad4 gives the highest support values, while coxl gives high support values and correct topology, but has a low level $(31 \%)$ of phylogenetically informative characters. The genes predicted to be uninformative are cox2, nad6 and the rRNA genes; they also have a small number of informative characters. The so-called "barcoding gene" coxl had the lowest proportion of phylogenetically informative positions. For population markers, cox3 is predicted to be a good alternative, but nad $4 L$ also has a high proportion of variable sites, with low variance in length. Sliding window analysis provided a rapid means of identifying 
novel oligonucleotide primers for capturing sequence variability in short PCR amplifications.

\section{Acknowledgements}

We are very grateful to Dr David Rollinson, Dr David Blair and an anonymous reviewer for critical comments on an earlier draft. Dr David Johnston provided DNA from $S$. japonicum, originally supplied to the NHM by Prof Manami Tanaka (formerly of the National Institute of Advanced Industrial Science and Technology, Tsukuba Science City, Japan). Dr Bonnie Webster kindly ran the PCR and gel to test the primer pairs. The idea for this project was initially conceived by DTJL and developed by MZZ for an MRes research project. MZZ led the research and conducted all phylogenetic analyses with guidance from TH and DTJL. TH developed the project further, led the sliding window analyses and guided data interpretation. The authors contributed equally to the preparation of the manuscript. MZZ was funded by Stiftelsen Olle Engkvist Byggmästare and Fredrika-Bremer-Förbundets Stipendiestiftelse. TH was funded through a Marie Curie Fellowship (Meif-ct-2004-501684) and DTJL through a Wellcome Trust Senior Research Fellowship (043965/Z/ 95/Z).

\section{References}

Abascal, F., Zardoya, R., Posada, D., 2005. ProtTest: selection of the best-fit models of protein evolution. Bioinformatics 21, 2104-2105.

Attwood, S.W., Upatham, E.S., Meng, X.H., Qiu, D.-C., Southgate, V.R., 2002. The phylogeography of Asian Schistosoma (Trematoda: Schistosomatidae). Parasitology 125, 99-112.

Avise, J.C., 2004. Molecular Markers, Natural History, and Evolution. Sinauer, Sunderland, MA.

Baker, R.H., DeSalle, R., 1997. Multiple sources of character information and the phylogeny of Hawaiian drosophilids. Syst. Biol. 46, 654-673.

Baker, R.H., Yu, X., DeSalle, R., 1998. Assessing the relative contribution of molecular and morphological characters in simultaneous analysis trees. Mol. Phylogenet. Evol. 9, 427-436.

Baker, R.H., Wilkinson, G.S., DeSalle, R., 2001. Phylogenetic utility of different types of molecular data used to infer evolutionary relationships among stalk-eyed flies (Diopsidae). Syst. Biol. 50, 87-105.

Ballard, J.W.O., 2000a. Comparative genomics of mitochondrial DNA in members of the Drosophila melanogaster subgroup. J. Mol. Evol. 51, $48-63$.

Ballard, J.W.O., 2000b. Comparative genomics of mitochondrial DNA in Drosophila simulans. J. Mol. Evol. 51, 64-75.

Ballard, J.W.O., Whitlock, M.C., 2004. The incomplete natural history of mitochondria. Mol. Ecol. 13, 729-744.

Barker, S.C., Blair, D., 1996. Molecular phylogeny of Schistosoma species supports traditional groupings within the genus. J. Parasitol. 82, 292-298.

Basch, P.F., 1991. Schistomes: Development, Reproduction and Host Relations. Oxford University Press, Oxford.

Bieberich, A.A., Minchella, D.J., 2001. Mitochondrial inheritance in Schistosoma mansoni: mitochondrial variable number tandem repeat mutation produces noise on top of the signal. J. Parasitol. 87, 1011-1015.

Bremer, K., 1994. Branch support and tree stability. Cladistics 10, 295-304.
Criscione, C.D., Blouin, M.S., 2004. Life cycles shape parasite evolution: comparative population genetics of salmon trematode. Evolution 58, 198-202.

Curtis, J., Minchella, D.J., 2000. Schistosome population genetic structure: when clumping worms is not just splitting hairs. Parasitol. Today $16,68-71$.

DeSalle, R., Schierwater, B. (Eds.), 1998. Molecular Approaches to Ecology and Evolution. Birkhäuser Verlag, Basel.

Dowton, M., Austin, A.D., 2002. Increased congruence does not necessarily indicate increased phylogenetic accuracy - the behavior of the incongruence length difference test in mixed-model analyses. Syst. Biol. 51, 19-31.

El-Sayed, N.M.A., Bartholomeu, D., Ivens, A., Johnston, D.A., LoVerde, P.T., 2004. Advances in schistosome genomics. Trends Parasitol. 20, $154-157$.

Farris, J.S., Kallersjo, M., Kluge, A.G., Bult, C., 1995. Constructing a significance test for incongruence. Syst. Biol. 44, 570-572.

Felsenstein, J., 1982. Numerical methods for inferring evolutionary trees. Quart. Rev. Biol. 57, 379-404.

Felsenstein, J., 1985. Confidence limits on phylogenies: an approach using the bootstrap. Evolution 39, 783-791.

Franco, G.R., Adams, M.D., Soares, M.B., Simpson, A.J., Venter, J.C., Peña, S.D., 1995. Identification of new Schistosoma mansoni genes by the EST strategy using a directional cDNA library. Gene 23, 141-147.

Hardman, M., Hardman, L.M., 2006. Comparison of the phylogenetic performance of neodermatan mitochondrial protein-coding genes. Zool. Scripta 35, 655-665.

Hebert, P.D.N., Gregory, T.R., 2005. The promise of DNA barcoding for taxonomy. Syst. Biol. 54, 852-859.

Hebert, P.D.N., Cywinska, A., Ball, S.L., deWaard, J.R., 2003a. Biological identifications through DNA barcodes. Proc. R. Soc. Lond. Ser. B 270, 313-321.

Hebert, P.D.N., Ratnasingham, S., deWaard, J.R., 2003b. Barcoding animal life: cytochrome c oxidase subunit 1 divergences among closely related species. Proc. R. Soc. Lond. Ser. B 270, S96-S99.

Hipp, A.L., Hall, J.C., Sytsma, K.J., 2004. Congruence versus phylogenetic accuracy: revisiting the incongruence length difference test. Syst. Biol. 53, 81-89.

Huelsenbeck, J.P., Ronquist, F., 2001. MRBAYES: Bayesian inference of phylogenetic trees. Bioinformatics 17, 754-755.

Iwagami, M., Monroy, C., Rosas, M.A., Pinto, M.R., Guevara, A.G., Vieira, J.C., Agatsuma, Y., Agatsuma, T., 2003. A molecular phylogeographic study based on DNA sequences from individual metacercariae of Paragonimus mexicanus from Guatemala and Ecuador. J. Helminthol. 77, 33-38.

Johnston, D.A., 2006. Genomes and genomics of parasitic flatworms. In: Maule, A.G., Marks, N.J. (Eds.), Parasitic Flatworms: Molecular Biology, Biochemistry, Immunology and Physiology. CAB International, Wallingford, pp. 37-80.

Jones, D.T., Taylor, W.R., Thornton, J.M., 1992. The rapid generation of mutation data matrices from protein sequences. Comput. Appl. Biosci. 8, 275-282.

Källersjö, M., Albert, V.A., Farris, J.S., 1999. Homoplasy increases phylogenetic structure. Cladistics 15, 91-93.

Khalil, L.F., 2002. Family Schistosomatidae Stiles \& Hassall, 1898. In Gibson, D.I., Jones, A., Bray, R.A. (Eds.), Keys to the Trematoda, vol. 1. CABI Publishing, Wallingford, pp. 419-432.

Kruger, F.J., Evans, A.C., 1990. Do all human urinary infections with Schistosoma mattheei represent hybridization between $S$. haematobium and S. mattheei? J. Helminthol. 64, 330-332.

Lee, M.S.Y., 2001. Uninformative characters and apparent conflict between molecules and morphology. Mol. Biol. Evol. 18, 676-680.

Le, T.H., Blair, D., Agatsuma, T., Humair, P.F., Campbell, N.J.H., Iwagami, M., Littlewood, D.T.J., Peacock, B., Johnston, D.A., Bartley, J., Rollinson, D., Herniou, E.A., Zarlenga, D.S., McManus, D.P., 2000a. Phylogenies inferred from mitochondrial gene orders - a cautionary tale from the parasitic flatworms. Mol. Biol. Evol. 17, $1123-1125$. 
Le, T.H., Blair, D., McManus, D.P., 2000b. Mitochondrial genomes of human helminths and their use as markers in population genetics and phylogeny. Acta Tropica 77, 243-256.

Le, T.H., Humair, P.F., Blair, D., Agatsuma, T., Littlewood, D.T.J., McManus, D.P., 2001. Mitochondrial gene content, arrangement and composition compared in African and Asian schistosomes. Mol. Biochem. Parasitol. 117, 61-71.

Littlewood, D.T.J., 2006. The evolution of parasitism in flatworms. In: Maule, A.G., Marks, N.J. (Eds.), Parasitic Flatworms: Molecular Biology, Biochemistry, Immunology and Physiology. CAB International, Wallingford, pp. 1-36.

Littlewood, D.T.J., Johnston, D.A., 1995. Molecular phylogenetics of the four Schistosoma species groups determined with partial 28S ribosomal RNA gene sequences. Parasitology 111, 167-175.

Littlewood, D.T.J., Olson, P.D., 2001. SSU rDNA and the Platyhelminthes: signal, noise, conflict and compromise. In: Littlewood, D.T.J., Bray, R.A. (Eds.), Interrelationships of the Platyhelminthes. Taylor \& Francis, London, pp. 292-301.

Littlewood, D.T.J., Lockyer, A.E., Webster, B.L., Johnston, D.A., Le, T.H., 2006. The complete mitochondrial genomes of Schistosoma haematobium and Schistosoma spindale and the evolutionary history of mitochondrial genome changes among parasitic flatworms. Mol. Phylogenet. Evol. 39, 452-467.

Lockyer, A.E., Olson, P.D., Littlewood, D.T.J., 2003a. Utility of complete large and small subunit rRNA genes in resolving the phylogeny of the Neodermata (Platyhelminthes): implications and a review of the cercomer theory. Biol. J. Linn. Soc. 78, $155-171$.

Lockyer, A.E., Olson, P.D., Østergaard, P., Rollinson, D., Johnston, D.A., Attwood, S.A., Southgate, V.R., Horak, P., Snyder, S.D., Le, T.H., Agatsuma, T., McManus, D.P., Carmichael, A.C., Naem, S., Littlewood, D.T.J., 2003b. The phylogeny of the Schistosomatidae based on three genes with emphasis on the interrelationships of Schistosoma Weinland, 1858. Parasitology 126, 203-224.

Maddison, W.P., Maddison, D.R., 2000. MacClade. Version 4. Sinauer Associates, Sunderland, Massachusetts.

Minchella, D.J., Lewis, F.A., Sollenberger, K.M., Williams, J.A., 1994. Genetic diversity of Schistosoma mansoni: quantifying strain heterogeneity using a polymorphic DNA element. Mol. Biochem. Parasitol. 68, 307-313.

Morgan, J.A.T., DeJong, R.J., Kazibwe, F., Mkoji, G.M., Loker, E.S., 2003. A newly-identified lineage of Schistosoma. Int. J. Parasitol. 33, 977-985.

Morgan, J.A.T., Dejong, R.J., Adeoye, G.O., Ansa, E.D.O., Barbosa, C.S., Bremond, P., Cesari, I.M., Charbonnel, N., Correa, L.R., Coulibaly, G., D’Andrea, P.S., De Souza, C.P., Doenhoff, M.J., File, S., Idris, M.A., Incani, R.N., Jarne, P., Karanja, D.M.S., Kazibwe, F., Kpikpi, J., Lwambo, N.J.S., Mabaye, A., Magalhaes, L.A., Makundi, A., Mone, H., Mouahid, G., Muchemi, G.M., Mungai, B.N., Sene, M., Southgate, V., Tchuente, L.A.T., Theron, A., Yousif, F., Magalhaes, E.M.Z., Mkoji, G.M., Loker, E.S., 2005. Origin and diversification of the human parasite Schistosoma mansoni. Mol. Ecol. 14, 3889-3902.

Moritz, C., Cicero, C., 2004. DNA barcoding: promise and pitfalls. PLoS Biol. 2, e354.

Oliveira, G., Rodrigues, N.B., Romanha, A.J., Bahia, D., 2004. Genome and genomics of schistosomes. Can. J. Zool. 82, 375.

Olson, P.D., Tkach, V.V., 2005. Advances and trends in the molecular systematics of the parasitic Platyhelminthes. Adv. Parasitol. 60, $165-243$.

Park, J.-K., Kim, K.-H., Kang, S.-H., Kim, J.-H., Eom, K.S., Littlewood, D.T.J., 2007. A common origin of complex life cycles in parasitic flatworms: evidence from the complete mitochondrial genome of Microcotyle sebastis. BMC Evol. Biol. 7, 11.

Pongratz, N., Storhas, M., Carranza, S., Michiels, N.K., 2003. Phylogeography of competing sexual and parthenogenetic forms of a freshwater flatworm: patterns and explanations. BMC Evol. Biol. 3,23 .
Rawlings, T.A., Collins, T.M., Bieler, R., 2003. Changing identities: tRNA duplication and remolding within animal mitochondrial genomes. Proc. Natl. Acad. Sci. USA 100, 15700-15705.

Reyes, A., Gissi, C., Pesole, G., Saccone, C., 1998. Asymmetrical directional mutation pressure in the mitochondrial genome of mammals. Mol. Biol. Evol. 15, 957-966.

Rodrigues, N.B., LoVerde, P.T., Romanha, A.J., Oliveira, G., 2002. Characterization of new Schistosoma mansoni microsatellite loci in sequences obtained from public DNA databases and microsatellite enriched genomic libraries. Mem. Inst. Oswaldo Cruz 97, 71-75.

Rodrigues, N.B., Silva, M.R., Pucci, M.M., Minchella, D.J., Sorensen, R., Loverde, P.T., Romanha, A.J., Oliveira, G., 2007. Microsatelliteenriched genomic libraries as a source of polymorphic loci for Schistosoma mansoni. Mol. Ecol. Notes 4, 263-265.

Rokas, A., Williams, B.L., King, N., Carroll, S.B., 2003. Genome-scale approaches to resolving incongruence in molecular phylogenies. Nature 425, 798-804.

Rozen, S., Skaletsky, H.J., 2000. Primer3 on the WWW for general users and for biologist programmers. In: Krawetz, S.M.S. (Ed.), Bioinformatics Methods and Protocols: Methods in Molecular Biology. Humana Press, Totowa, NJ, pp. 365-386.

Sakamoto, Y., Ishiguro, M., Kitagawa, G., 1986. Akaike Information Criterion Statistics. Kluwer Academic, Dordrecht, Netherlands.

Semyenova, S.K., Morozova, E.V., Chrisanfova, G.G., Asatrian, A.M., Movsessian, S.O., Ryskov, A.P., 2003. RAPD variability and genetic diversity in two populations of liver fluke, Fasciola hepatica. Acta Parasitol. 48, 125-130.

Sørensen, E., Bøgh, H.O., Johansen, M.V., McManus, D.P., 1999. PCRbased identification of individuals of Schistosoma japonicum representing different subpopulations using a genetic marker in mitochondrial DNA. Int. J. Parasitol. 29, 1121-1128.

Sorensen, R.E., Rodrigues, N.B., Oliveira, G., Romanha, A.J., Minchella, D.J., 2006. Genetic filtering and optimal sampling of Schistosoma mansoni populations. Parasitology 133, 443-451.

Spotila, L.D., Rekosh, D.M., LoVerde, P.T., 1991. Polymorphic repeated DNA element in the genome of Schistosoma mansoni. Mol. Biochem. Parasitol. 48, 117-120.

SPSS, 2004. Statistical Package for the Social Sciences. SPSS, Inc., Chicago, IL.

Srivastava, J., Gower, C.M., Balolong, E., Wang, T.P., Qian, B.Z., Webster, J.P., 2005. Population genetics of multi-host parasites - the case for molecular epidemiological studies of Schistosoma japonicum using larval stages from naturally infected hosts. Parasitology 131, 617-626.

Swofford, D.L., 2002. PAUP*. Phylogenetic Analysis Using Parsimony *and Other Methods. Sinauer Associates, Sunderland, Massachusetts.

Szczepanik, D., Mackiewicz, P., Kowalczuk, M., Gierlik, A., Nowicka, A., Dudek, M.R., Cebrat, S., 2001. Evolution rates of genes on leading and lagging DNA strands. J. Mol. Evol. 52, 426-433.

Theron, A., Sire, C., Rognon, A., Prugnolle, F., Durand, P., 2004. Molecular ecology of Schistosoma mansoni transmission inferred from the genetic composition of larval and adult infrapopulations within intermediate and definitive hosts. Parasitology 129, 571-585.

Thompson, J.D., Higgins, D.G., Gibson, T.J., 1994. CLUSTAL W: improving the sensitivity of progressive multiple sequence alignment through sequence weighting, positions-specific gap penalties and weight matrix choice. Nucl. Acids Res. 22, 4673-4680.

Torroni, A., Achilli, A., Macaulay, V., Richards, M., Bandelt, H.-J., 2006. Harvesting the fruit of the human mtDNA tree. Trends Genet. 22, 339-345.

Vilas, R., Paniagua, E., Sanmartin, M.L., 2003. Genetic variation within and among infrapopulations of the marine digenetic trematode Lecithochirium fusiforme. Parasitology 126, 465-472.

Webster, B.L., Southgate, V., Littlewood, D.T.J., 2006. A revision of the interrelationships of Schistosoma including the recently described Schistosoma guineensis. Int. J. Parasitol. 36, 947-955.

Wenzel, J.W., Siddall, M.E., 1999. Noise. Cladistics 15, 51-64. 
WHO, 2001. The World Health Report 2001. Mental Health: new understanding, new hope. World Health Organization, Geneva.

Wickström, L.M., Haukisalmi, V., Varis, S., Hantula, J., Fedorov, V.B., Hentonnen, H., 2003. Phylogeography of the circumpolar Paranoplocephala arctica species complex (Cestoda: Anoplocephalidae) parasitizing collared lemmings (Dicrostonyx spp.). Mol. Ecol. 12, $3359-3371$
Will, K.W., Mishler, B.D., Wheeler, Q.D., 2005. The perils of DNA barcoding and the need for integrative taxonomy. Syst. Biol. 54, 844851.

Xia, X., Xie, Z., 2001. DAMBE: software package for data analysis in molecular biology and evolution. J. Heredity 92, 371-373.

Xia, X., Xie, Z., Salemi, M., Chen, L., Wang, Y., 2003. An index of substitution saturation and its application. Mol. Phylogenet. Evol. 26, 1-7. 